\title{
Multimolecular Aggregation of Mononucleosomal DNA in Concentrated Isotropic Solutions
}

\author{
Petra Wissenburg ${ }^{\dagger}$ and Theo Odijk* \\ Department of Polymer Technology, Faculty of Chemical Engineering and Materials Science,
} Delft University of Technology, P.O. Box 5045, 2600 GA Delft, The Netherlands

\section{Peter Cirkel and Michel Mandel}

Department of Physical and Macromolecular Chemistry, Gorlaeus Laboratories, University of Leiden, P.O. Box 9502, 2300 RA Leiden, The Netherlands

Received August 19, 1994; Revised Manuscript Received December 29, $1994^{\otimes}$

\begin{abstract}
We study semidilute and concentrated solutions of mononucleosomal DNA at three different $\mathrm{NaCl}$ concentrations by static and dynamic light scattering, viscosity, and electron cryomicroscopy. At low enough DNA concentrations the second virial coefficient behaves in the usual manner and can be interpreted by a charged rod model. It is possible to understand the concentration and scattering vector dependence of the scattering with the help of recent theoretical analyses of semidilute solutions of charged rods. Moreover, the mutual friction coefficient is in accord with the theory of hydrodynamic screening. At a certain critical concentration which increases with added salt, the intensity of the equilibrium static scattering increases several 100 -fold, indicating the DNA aggregates. The dynamic scattering is in line with the static scattering; a very long decay time seems to be associated with the DNA aggregates. Freeze electron micrographs definitely bear out the existence of DNA globules which appear to form loose aggregates. Precautions have been taken to ensure there are no spurious contaminants to the best of our knowledge. Long-range attractive forces between polyions have been postulated recently within the framework of a semiquantitative theory; these ideas are tested by analyzing the ionic-strength dependence of the third virial coefficient and the onset of aggregation.
\end{abstract}

\section{Introduction}

For some time, double-stranded DNA has been suspected of aggregating under conditions where this is unlikely to occur from a balance between electrostatic and dispersion forces. Mandelkern et al. ${ }^{1}$ concluded from their rotational relaxation times in solutions of sonicated DNA at low salt that DNA may aggregate into bundles containing seven DNA rods although they neglected to account for ionic friction. In the same year Fulmer et al. ${ }^{2}$ measured strong slow decays in the dynamic light scattering by DNA suspensions below $10^{-2} \mathrm{M}$ simple salt. Sonicated calf-thymus DNA actually gels without liquid-crystalline order at nondilute concentrations, as has been established rheometrically. 3,4 By monitoring the steady-state fluorescence polarization, Härd and Kearns ${ }^{5}$ deduced that monodisperse DNA must start to aggregate at a DNA concentration of $5 \mathrm{~g} / \mathrm{L}$ in $1 \mathrm{M} \mathrm{NaCl}$. Nicolai and Mandel ${ }^{6}$ thought DNA might be aggregating at low salt and nondilute DNA concentrations because the static scattering started to increase once the DNA solution was allowed to remain quiescent after filtration. Contrastingly, the scattering intensity of a flowing suspension was constant: presumably, the aggregates break up under shear. An analogous effect ${ }^{7}$ was witnessed (and corroborated ${ }^{8,9}$ ) in later dynamic scattering experiments. After filtration of a DNA suspension, a slow mode gradually built up if the solution was left undisturbed. Other anomalies have been seen in semidilute DNA solutions which may be related to aggregation: the "precholesteric" DNA phase, ${ }^{10}$ peculiarities in the NMR relaxation rates, ${ }^{11}$ and the existence of an unexplained "region II" during DNA sedimentation. ${ }^{12}$ Recently, we

\footnotetext{
${ }^{+}$Present address: Unilever Research Laboratory, Olivier van Noortlaan 120, 3133 AT Vlaardingen, The Netherlands.

${ }^{\otimes}$ Abstract published in Advance ACS Abstracts, February 15, 1995.
}

presented a short preview on concentrated DNA solutions at $1 \mathrm{M} \mathrm{NaCl}$ in which we displayed DNA aggregates explicitly in an electron micrograph. ${ }^{13}$ The solutions appeared to be free from contaminants. ${ }^{13}$ The current paper elaborates on this work.

Recent theoretical work by one of us $^{14}$ postulates a long-range attractive force between polyelectrolyte molecules in order to explain the strongly anomalous ionicstrength dependence of the third virial coefficient of xanthan ${ }^{15}$ and the existence of a hexagonal phase of tobacco mosaic virus. ${ }^{16}$ Though the origin of the attractive interaction is a mystery, we here show that we are able to rationalize the onset of DNA aggregation with the help of a stability criterion based on this theory. In particular, its ionic-strength dependence is consistent with that needed to explain the peculiar behavior of other polyelectrolytes. ${ }^{14-16}$ We study the complex aggregational behavior of semidilute and concentrated mononucleosomal DNA by static and dynamic light scattering, viscosity, and electron cryomicroscopy.

\section{Experimental}

Mononucleosomal DNA was isolated in gram amounts from nucleosome core particles by digestion of calf-thymus chromatin with micrococcal nuclease according to the method described by Wang et al. ${ }^{17}$ Characterization by a combination of gel permeation chromatography and low-angle laser light scattering showed that the DNA had a molar mass of about $1.07 \times 10^{5} \mathrm{~g} \mathrm{~mol}^{-1}$. The UV absorbance ratio $A_{260} / A_{280}$ of the sample was 1.91 , indicating that the sample was free from protein. The final pellet was resuspended in a buffer containing $50 \mathrm{mM} \mathrm{NaCl}, 24 \mathrm{mM}$ EDTA. Salt-free DNA was obtained by prolonged dialysis at $4{ }^{\circ} \mathrm{C}$ of the resulting suspension against water of millipore quality until the conductance of the outer solution equaled that of pure water. In order to avoid possible denaturation of the DNA during the dialysis, the DNA concentration was never below $22 \mathrm{~g} / \mathrm{L}$. Melting experiments showed a hypochromic effect of $30.2 \%$, indicating that the DNA was double-stranded. The concentration of $\mathrm{Ca}^{2+}$ ions was in 
general too low to be detectable by atomic absorption spectroscopy. In a few cases we detected the presence of one $\mathrm{Ca}^{2-}$ ion per ten DNA molecules, i.e. less than $0.04 \%$ of the $\mathrm{Na}^{+}$ counterion concentration. The solution was further concentrated and freeze-dried.

The DNA concentrations in this study extend to just below the isotropic-cholesteric transition. These high DNA concentrations made dialysis of the samples virtually impossible, resulting in either the dilution of the solutions or the penetration of the DNA through the dialysis membranes. We therefore decided to refrain from dialysis altogether and to add the desired $\mathrm{NaCl}$ solution to the salt-free DNA. Another related problem arising from these high DNA concentrations is the contribution of the "uncondensed" counterions of the DNA to the overall ionic strength of the solution. For instance, in the case of the $0.01 \mathrm{M} \mathrm{NaCl}$ series this contribution already reaches an ion concentration equimolar to the salt solution at about $30 \mathrm{~g} / \mathrm{L}$ DNA. At higher DNA concentrations the ionic strength is mainly determined by the counterions and thus depends on the DNA concentration, more or less as in a solution without added salt. In the $0.1 \mathrm{M} \mathrm{NaCl}$ series the crossover is at roughly $300 \mathrm{~g} / \mathrm{L} \mathrm{DNA}$. Only for the $1 \mathrm{M} \mathrm{NaCl}$ series may we assume excess salt conditions at all DNA concentrations.

Static light scattering experiments at zero scattering angle were performed at three salt concentrations: $1,0.1$, and 0.01 $\mathrm{M} \mathrm{NaCl}$. In each case we prepared the most concentrated solution first by dissolving salt-free DNA in the respective aqueous $\mathrm{NaCl}$ solution. We started to carry out our scattering experiments only after an equilibration time of $24 \mathrm{~h}$. Just after these measurements the concentration of the solution was determined more precisely from the UV absorbance at $260 \mathrm{~nm}$ using an extinction coefficient of $20 \mathrm{mg} \mathrm{mL}^{-1} \mathrm{~cm}^{-1}$. Errors in the DNA concentration are estimated to be less then $2 \%$. Subsequently, we diluted the solution and performed a new scattering experiment. By repeating these actions three series of solutions of concentrations descending from 150 to $0.80 \mathrm{~g} / \mathrm{L}$ in $1 \mathrm{M}$, from 118 to $0.56 \mathrm{~g} / \mathrm{L}$ in $0.1 \mathrm{M}$, and from 109 to 0.23 $\mathrm{g} / \mathrm{L}$ in $0.01 \mathrm{M} \mathrm{NaCl}$ were investigated. All solutions remained isotropic: none was birefringent between two crossed polarizers.

The static light scattering experiments were performed at zero scattering angle with a Chromatix KMX-6 low-angle laser light scattering photometer whose light source is a $\mathrm{He}-\mathrm{Ne}$ laser at a wavelength of $633 \mathrm{~nm}$. The sample cell consisted of two thick silica windows separated by a Teflon spacer. The samples were brought into the measuring cell of the KMX-6 by continuous pumping through $0.22 \mu \mathrm{m}$ Millipore (Millex-GV) filters. We started our measurements after the flow had stopped. At all ionic strengths, the scattering intensity of the concentrated solutions at first started to increase with time after filtration; ultimately, we measured the final intensity after it had shown no significant change for several hours. The intensity of the solutions which were more dilute remained constant from the start and was measured within $1 \mathrm{~h}$. The quantity determined was the ratio of the scattered to the transmitted radiant power from which the Rayleigh factor $R_{0}$ was computed with the help of the geometric parameters of the instrument. No reference to external standards or arbitrary calibration factors was required. We expressed the scattered intensity in terms of the usual quantity $K c / R_{0}$, in which $c$ is the polymer concentration (in $\mathrm{g} / \mathrm{mL}$ ) but where $K$ is considered to be a concentration dependent factor. The refractive index was determined as a function of the DNA concentration at the three salt concentrations used earlier, with a Pulfrich refractometer modified for use with a $633 \mathrm{~nm}$ $\mathrm{He}-\mathrm{Ne}$ laser source. The refractive index has the same dependence on the DNA concentration at all ionic strengths, as is shown in Figure 1. At high DNA concentrations the increase in the refractive index $n$ of the solution compared with $n_{0}$ of the respective $\mathrm{NaCl}$ solution was found to deviate slightly but significantly from a linear dependence with DNA concentration. Accordingly, we determined the refractive index increment $\mathrm{d} n / \mathrm{d} c$ as a function of the DNA concentration from the slope of $n$ versus $c$ (see Figure 1). Next, a concentration dependent $K$ was calculated from the experimentally deter-

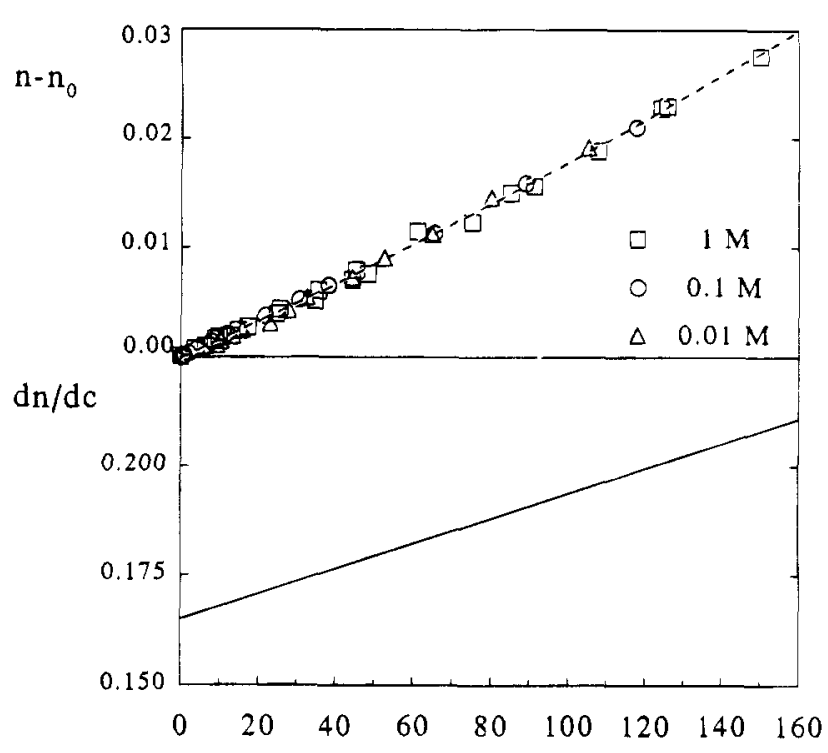

$\mathrm{c}(\mathrm{g} / 1)$

Figure 1. (Upper diagram) Increase $\left(n-n_{0}\right)$ of the refractive index of the DNA solutions with respect to that of the respective $\mathrm{NaCl}$ solutions as a function of DNA concentration at $25{ }^{\circ} \mathrm{C}$. The dashed line is a second-order polynomial fit. In the lower diagram the calculated refractive index increment $\mathrm{d} n / \mathrm{d} c$ depends linearly on the DNA concentration.

mined $n$ and $\mathrm{d} n / \mathrm{d} c$, in accordance with a recent scattering theory of nondilute solutions. ${ }^{18}$

Dynamic light scattering experiments were performed at $\mathrm{NaCl}$ concentrations 1 and $0.01 \mathrm{M}$. We prepared stock solutions of high DNA concentration by dissolving salt-free DNA in the two salt solutions. After an equilibration time of $24 \mathrm{~h}$, the stock solution was filtered through a $0.22 \mu \mathrm{m}$ Millipore (Millex-GV) filter into carefully cleaned cuvettes and diluted with filtered salt solution, resulting in two series with DNA concentrations ranging from 1.73 to $117 \mathrm{~g} / \mathrm{L}$ at $1 \mathrm{M}$ and from 7.55 to $101 \mathrm{~g} / \mathrm{L}$ at $0.01 \mathrm{M} \mathrm{NaCl}$. The solutions were allowed to remain undisturbed for 1 or 2 days before the measurements were performed, taking due care of an equilibration of the temporal phenomena encountered after filtration in the static light scattering experiments. The dynamic light scattering experiments were performed with a spectrometer consisting of an ALV goniometer and an ALV 5000 correlator. The light source was an Ar-ion laser (Spectra Physics, 2000 series) at the $514.5 \mathrm{~nm}$ line, linearly polarized perpendicular to the scattering plane. Typically, laser power was about 150 $\mathrm{mW}$. Scattering was done at angles between 30 and $150^{\circ}$. The reduced intensity-time correlation functions $g_{2}(t)$ were recorded with the time axis logarithmically spaced. In this socalled "multi- $\tau$ " mode the sample time in the first 16 channels was $12.5 \mathrm{~ns}$. The sample time was doubled every further set of eight channels, reaching a total time of several seconds. If the scattered light satisfies Gaussian statistics, we can relate the reduced intensity-time correlation function $g_{2}(t)$ to the reduced field-time correlation function $g_{1}(t)$ via the so-called Siegert relation:

$$
\begin{gathered}
g_{2}(t)=\frac{\left\langle I_{\mathrm{S}}(0) I_{\mathrm{S}}(t)\right\rangle}{\langle I\rangle^{2}} \quad g_{1}(t)=\frac{\left\langle E^{*}{ }_{\mathrm{S}}(0) \cdot E_{\mathrm{S}}(t)\right\rangle}{\langle I\rangle} \\
g_{2}(t)=1+\alpha\left|g_{1}(t)\right|^{2}
\end{gathered}
$$

where $\alpha$ is a factor summarizing data related to the apparatus. The dynamics of the solution are expressed via the correlation function $g_{1}(t)$. At high DNA concentrations the correlation functions clearly exhibited more than one decay rate:

$$
g_{1}(t)=\sum_{i} A_{\mathrm{i}} \mathrm{e}^{-\Gamma_{i} t}
$$


At first we examined the correlation functions provisionally in a qualitative way. To analyze the apparent diffusion coefficient $\Gamma_{i} / q^{2}$ more quantitatively, we applied CONTINanalyse ${ }^{19}$ to the correlation function $g_{1}(t)$. Decay rates were determined from the positions of the peaks.

Static light scattering experiments as a function of scattering angle were performed on the same solutions (but not on a similar series at $0.1 \mathrm{M} \mathrm{NaCl}$ ) and using the same spectrometer as in the dynamic light scattering experiments, although with larger scattering volumes. The angular dependence is expressed via the scattering vector of magnitude $q=\left(4 \pi n / \lambda_{0}\right)$ $\sin (\theta / 2)$. The Rayleigh ratio $R(q)$ of the solute is calculated from the ratio $r(q)$ of the scattered intensity $I_{\mathrm{sc}}$ to the intensity

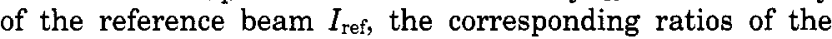
solvent $r$ (sol) and the toluene standard $r$ (st), and the Rayleigh ratio $R$ (st) of toluene:

$$
R(q)=\frac{(r(q)-r(\mathrm{sol}))}{r(\mathrm{st})} R(\mathrm{st})
$$

Accordingly, we determined absolute values of the structure factor $S(q)$ :

$$
S(q)=\frac{1}{M} \frac{R(q)}{K c}
$$

Note that the factor $K$ used here is corrected for the scattering volume of the cylindrical cuvettes. The value for $M$ employed in this calculation is $1.07 \times 10^{5} \mathrm{~g} \mathrm{~mol}^{-1}$, the molar mass of mononucleosomal DNA determined earlier. All scattering experiments were performed at $25^{\circ} \mathrm{C}$.

Viscosity measurements were performed at $1 \mathrm{M} \mathrm{NaCl}$. The DNA concentrations span the entire concentration regime addressed in the light scattering experiments. In one experiment, the solutions were allowed to reach equilibrium before measurement; in another, the measurements were carried out just after filtration. The experimental setup was a Haake CV 100 rotation viscosimeter. Shear rates between 0 and $300 \mathrm{~s}^{-1}$ were probed. The viscosity is independent of the shear rate for all solutions, i.e. all solutions display Newtonian behavior. The results are repeatable.

Electron cryomicroscopy was performed on DNA solutions of 144 and $37.3 \mathrm{~g} / \mathrm{L}$ at $1 \mathrm{M}$ and $74.5 \mathrm{~g} / \mathrm{L}$ at $0.01 \mathrm{M} \mathrm{NaCl}$, in order to investigate possible aggregation phenomena. The solutions were prepared by dissolving salt-free DNA in the particular salt solution and then filtered through $0.22 \mu \mathrm{m}$ Millipore filters (Millex-GV) so as to mimic the same conditions as in the scattering experiments. They were allowed to reach equilibrium before freezing. The DNA suspensions were applied to copper platelets and cryo-fixed by rapid freezing $\left(10^{5}\right.$ $\mathrm{K} / \mathrm{s}$ ) in liquid propane, using the plunging method. Next, we put the frozen samples in a Baltzers BAF400D freeze etching device (Baltzers, Liechtenstein) at a sample temperature of $-150^{\circ} \mathrm{C}$ and a pressure of $2.5 \times 10^{-5} \mathrm{~Pa}$. In some experiments the surface of the frozen sample was shadowed by platinum carbon evaporation $(2.5 \mathrm{~nm} \mathrm{Pt})$ at an angle of $45^{\circ}$, either directly or after etching for $30 \mathrm{~s}$. In others the samples were broken and the fresh surfaces were shadowed in the same manner. In order to strengthen the replicas, a $30 \mathrm{~nm}$ carbon layer was evaporated onto the surface. After thawing, the replicas were cleaned overnight in water or a $30 \%$ sodium hypochlorite solution. The replicas were examined by means of a transmission electron microscope (Philips EM410, Eindhoven, The Netherlands), the images being recorded at a magnification of $31000 \times$ and photographically enlarged.

\section{Results}

A. Static Light Scattering at Zero Scattering Angle. The inverse scattering intensity $K c / R_{0}$ is plotted against the DNA concentration in Figures $2 \mathrm{a}-\mathrm{c}$ at three salt concentrations $(1,0.1$, and $0.01 \mathrm{M} \mathrm{NaCl})$. The values of $K c / R_{0}$ are listed in Table 1 . At all three ionic strengths and at low DNA concentrations, the curves behave as one would expect. Extrapolation of $K c / R_{0}$ to
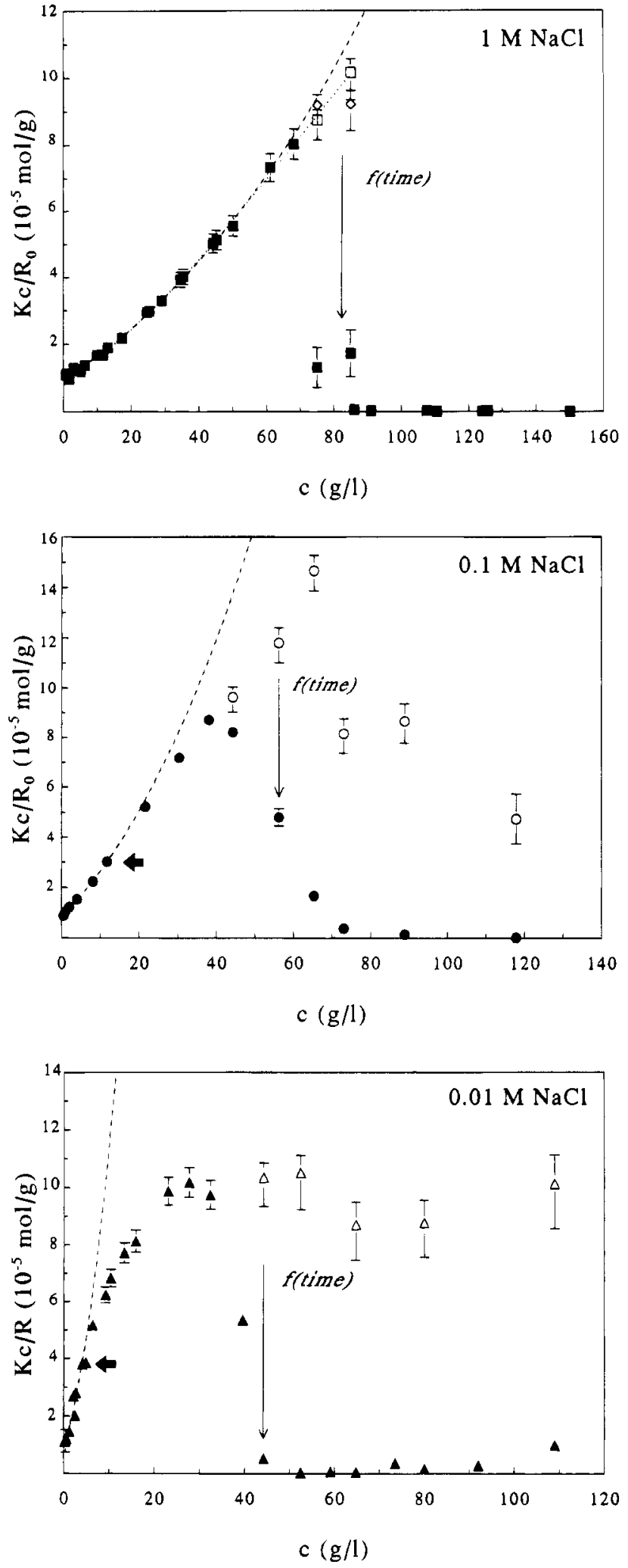

Figure 2. (a, top) Inverse specific intensity $K c / R_{0}$ at zero scattering angle as a function of the DNA concentration at 1 $\mathrm{M} \mathrm{NaCl}$ at $25^{\circ} \mathrm{C}$. The filled symbols represent equilibrium values; the open symbols, values just after filtration. The dashed line is a second-order polynomial fit for concentrations up to $68 \mathrm{~g} / \mathrm{L}$. (b, middle) Same as (a) but at $0.1 \mathrm{M} \mathrm{NaCl}$. The second-order polynomial is fitted up to a concentration of 12 $\mathrm{g} / \mathrm{L}$ (indicated by thick arrow). (c, bottom) Same as (a) but at $0.01 \mathrm{M} \mathrm{NaCl}$. The second-order polynomial is fitted up to a concentration of $5 \mathrm{~g} / \mathrm{L}$ (indicated by thick arrow).

zero DNA concentration yields the correct molar mass of $M=1.07 \times 10^{5} \mathrm{~g} / \mathrm{mol}$ for a 160 base pair fragment ${ }^{17}$ 
Table 1. Inverse Scattering Intensity $K c / R_{0}$ at Zero Scattering Angle as a Function of DNA Concentration at Three Salt Concentrations and at $25{ }^{\circ} \mathrm{C}$

\begin{tabular}{|c|c|c|c|c|c|c|c|c|}
\hline \multicolumn{3}{|c|}{$1 \mathrm{M} \mathrm{NaCl}$} & \multicolumn{3}{|c|}{$0.1 \mathrm{M} \mathrm{NaCl}$} & \multicolumn{3}{|c|}{$0.01 \mathrm{M} \mathrm{NaCl}$} \\
\hline \multirow[b]{2}{*}{$c(\mathrm{~g} / \mathrm{L})$} & \multicolumn{2}{|c|}{$K c / R_{0}\left(10^{-5} \mathrm{~mol} / \mathrm{g}\right)$} & \multirow[b]{2}{*}{$c(\mathrm{~g} / \mathrm{L})$} & \multicolumn{2}{|c|}{$K c / R_{0}\left(10^{-5} \mathrm{~mol} / \mathrm{g}\right)$} & \multirow[b]{2}{*}{$c(\mathrm{~g} / \mathrm{L})$} & \multicolumn{2}{|c|}{$K c / R_{0}\left(10^{-5} \mathrm{~mol} / \mathrm{g}\right)$} \\
\hline & equil & $\begin{array}{l}\text { just after } \\
\text { filtration }\end{array}$ & & equil & $\begin{array}{l}\text { just after } \\
\text { filtration }\end{array}$ & & equil & $\begin{array}{l}\text { just after } \\
\text { filtration }\end{array}$ \\
\hline 0.80 & 1.09 & & 0.56 & 0.89 & & 0.23 & 1.11 & \\
\hline 1.09 & 1.13 & & 0.97 & 1.04 & & 0.43 & 1.14 & \\
\hline 1.55 & 1.06 & & 2.05 & 1.23 & & 0.69 & 1.21 & \\
\hline 3.14 & 1.29 & & 4.01 & 1.54 & & 1.31 & 1.48 & \\
\hline 4.71 & 1.23 & & 8.11 & 2.24 & & 1.83 & 3.34 & \\
\hline 5.12 & 1.19 & & 11.8 & 3.03 & & 2.21 & 2.69 & \\
\hline 6.43 & 1.37 & & 21.7 & 5.22 & & 2.56 & 2.02 & \\
\hline 9.94 & 1.68 & & 30.3 & 7.18 & & 2.77 & 2.81 & \\
\hline 11.8 & 1.69 & & 38.0 & 8.72 & & 4.11 & 3.80 & \\
\hline 13.2 & 1.91 & & 44.2 & 8.22 & 9.63 & 4.95 & 3.86 & \\
\hline 17.3 & 2.18 & & 56.2 & 4.80 & 11.80 & 6.46 & 5.17 & \\
\hline 24.7 & 2.95 & & 65.3 & 1.67 & 14.66 & 9.34 & 6.24 & \\
\hline 25.4 & 2.99 & & 73.0 & 0.37 & 8.16 & 10.5 & 6.83 & \\
\hline 29.0 & 3.30 & & 88.9 & 0.10 & 8.66 & 13.4 & 7.72 & \\
\hline 34.5 & 3.94 & & 118 & 0.022 & 4.73 & 16.0 & 8.13 & \\
\hline 35.4 & 4.03 & & & & & 23.1 & 9.88 & \\
\hline 44.2 & 5.03 & & & & & 27.7 & 10.18 & \\
\hline 45.2 & 5.14 & & & & & 32.4 & 9.75 & \\
\hline 50.1 & 5.56 & & & & & 44.2 & 0.53 & 10.35 \\
\hline 61.0 & 7.34 & & & & & 52.5 & 0.023 & 10.51 \\
\hline 68.1 & 8.05 & & & & & 59.1 & 0.059 & \\
\hline 75.0 & 1.31 & 8.78 & & & & 64.8 & 0.044 & 8.70 \\
\hline 85.0 & 1.73 & 10.18 & & & & 80.0 & 0.16 & 8.77 \\
\hline 91.1 & 0.025 & & & & & 92.0 & 0.28 & \\
\hline 108 & 0.036 & & & & & 109 & 0.99 & \\
\hline 111 & 0.006 & & & & & & & \\
\hline 124 & 0.010 & & & & & & & \\
\hline 150 & 0.006 & & & & & & & \\
\hline
\end{tabular}

Table 2. Results from Static Light Scattering at Zero Scattering Angle and at $25{ }^{\circ} \mathrm{C}$

\begin{tabular}{lccc}
\hline & $\begin{array}{c}M \\
\left(10^{5} \mathrm{~g} \mathrm{~mol}^{-1}\right)\end{array}$ & $\begin{array}{c}A_{2} \\
\left(10^{-6} \mathrm{~L} \mathrm{~mol} \mathrm{~g}^{-2}\right)\end{array}$ & $\begin{array}{c}A_{3} \\
\left(10^{-9} \mathrm{~L}^{2} \mathrm{~mol} \mathrm{~g}^{-3}\right)\end{array}$ \\
\hline & \multicolumn{3}{c}{ Second-Order Polynomial Fits } \\
$0.1 \mathrm{M} \mathrm{NaCl}$ & $1.05( \pm 0.03)$ & $0.30( \pm 0.02)$ & $2.3( \pm 0.2)$ \\
$0.01 \mathrm{M} \mathrm{NaCl}$ & $1.09( \pm 0.03)$ & $0.69( \pm 0.05)$ & $11.5( \pm 2.0)$ \\
& $1.07( \pm 0.05)$ & $2.9( \pm 0.3)$ & $170( \pm 70)$ \\
$1 \mathrm{M} \mathrm{NaCl}$ & \multicolumn{4}{c}{ Third-Order Polynomial Fit } \\
& $1.00( \pm 0.05)$ & $0.26( \pm 0.06)$ & $4.0( \pm 0.5)$ \\
& with $A_{4}=-1.5( \pm 0.5) \times 10^{-11} \mathrm{~L}^{3} \mathrm{~mol} \mathrm{~g}^{-3}$
\end{tabular}

within the margin of error and irrespective of the $\mathrm{NaCl}$ concentration. The data points at low DNA concentrations fall on straight lines whose slopes yield the second virial coefficients $A_{2}$. The slope increases with decreasing ionic strength, which reflects the increasing effective diameter of the rodlike DNA molecules as the electrostatic screening diminishes. At moderate DNA concentrations all three scattering curves deviate from linear which may be attributed to the influence of the third virial coefficient $A_{3}$. Note that at 0.1 , but especially at $0.01 \mathrm{M} \mathrm{NaCl}$, the curvature of the plots may be misleading. The counterions then often contribute substantially to the total ionic strength of the solution, causing in effect a lowering of the slope in the scattering curve. We determined the second and third virial coefficients by applying second-order polynomial fits to the experimental data applicable to DNA concentrations where the ionic strength is given in the main by the concentration of added salt (see Table 2). The second virial coefficients $A_{2}$, are in agreement with the values found by Ferrari and Bloomfield ${ }^{20}$ and Nicolai and Mandel. ${ }^{6}$ Recall that these studies cover merely low DNA concentrations. Both the second and third virial coefficients increase with decreasing ionic strength.

In Figure $2 a-c$ we see that in contrast to the scattering at low DNA concentrations, strong anomalies occur at certain critical concentrations and beyond: the intensity of the scattered light is enhanced immediately after filtration. Initially, the increase is rapid but the intensity reaches a plateau slowly after 1 or 2 days, the ultimate equilibrium values exceeding the initial value by more than 2 orders of magnitude. It is possible to measure both the initial and the equilibrium values at the two lowest ionic strengths. At $1 \mathrm{M}$ this is feasible only in the transition region $(75-85 \mathrm{~g} / \mathrm{L})$, for at higher concentrations the intensity simply increases too fast. At all ionic strengths the equilibrium intensity fluctuates strongly. The time needed to reach equilibrium increases with the DNA concentration but is not very sensitive to the salt concentration. The inverse scattering immediately after filtration is definitely lower than expected on the basis of a smooth extrapolation of the equilibrium data at low DNA concentrations (Figure 2). At $1 \mathrm{M} \mathrm{NaCl}$, when the interpretation is not hampered by uncondensed counterions arising from the DNA, we tentatively account for this deviation by allowing for a fourth virial coefficient and applying a third-order polynomial fit to the data up to $85 \mathrm{~g} / \mathrm{L}$. The results are given in Table 2. In this provisional fit the values for the molar mass and the second virial coefficient are hardly modified and the value of the third virial coefficient increases slightly, whereas the fourth virial coefficient is negative.

The critical concentration at which the anomalies start to occur increases with the ionic strength (Figure 2) but the equilibrium values of $K c / R_{0}$ beyond the transition are of comparable magnitude $\left(<10^{-6} \mathrm{~mol} \mathrm{~g}^{-1}\right)$ for all three salt concentrations. In the concentration regimes investigated in this study, none of the DNA solutions shows any signs of phase separation, all of them remaining clear and isotropic at all times. At 1 $\mathrm{M} \mathrm{NaCl}$ the isotropic-to-cholesteric transition is first 


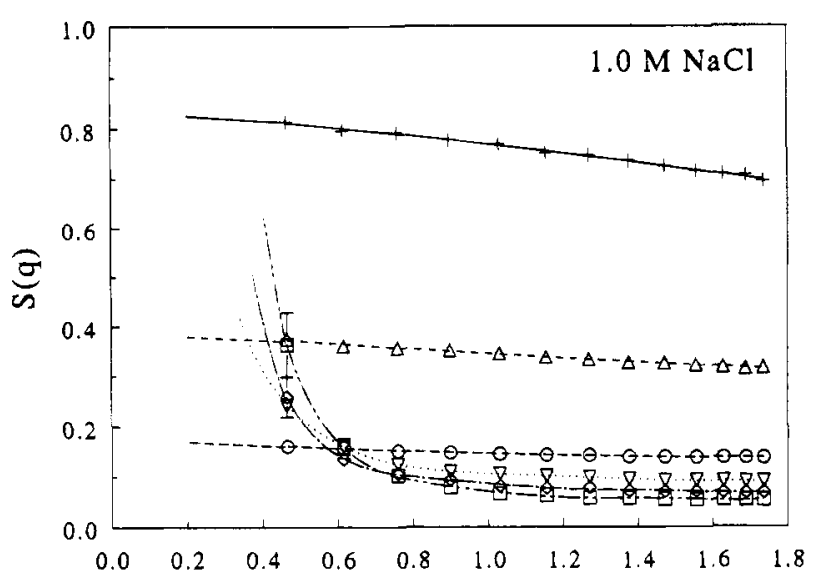

$\mathrm{qL}$

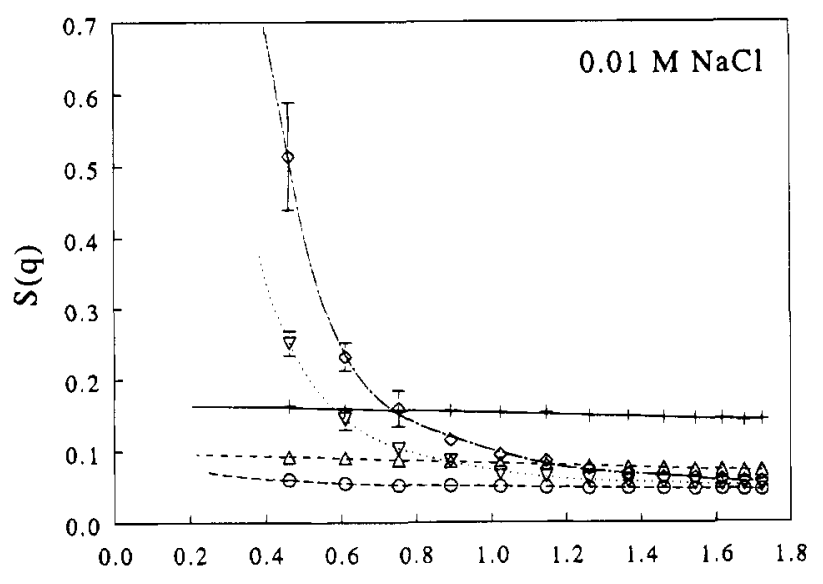

qL

Figure 3. (a, top) Structure factor $S(q)$ as a function of $q L$, with $L=54 \mathrm{~nm}$ the length of a single DNA molecule, for several DNA concentrations at $1 \mathrm{M} \mathrm{NaCl}:(+) 1.73 \mathrm{~g} / \mathrm{L},(\Delta)$ $22.0 \mathrm{~g} / \mathrm{L},(\bigcirc) 48.7 \mathrm{~g} / \mathrm{L},(\nabla) 71.5 \mathrm{~g} / \mathrm{L},(\diamond) 90.4 \mathrm{~g} / \mathrm{L}$, and $(\square) 117$ $\mathrm{g} / \mathrm{L}$. (b, bottom) Same as (a) but at $0.01 \mathrm{M} \mathrm{NaCl}$ : (+) 7.55 $\mathrm{g} / \mathrm{L},(\Delta) 21.3 \mathrm{~g} / \mathrm{L},(0) 42.8 \mathrm{~g} / \mathrm{L},(\nabla) 73.3 \mathrm{~g} / \mathrm{L}$, and $(\diamond) 101 \mathrm{~g} / \mathrm{L}$.

encountered at about $170 \mathrm{~g} / \mathrm{L}{ }^{35}$ Since the intensity scales with the number of scattering particles times their molar mass squared, the enormous increase in scattering intensities at high concentrations may be rationalized by postulating a considerable increase in the molar mass of the scattering particles. Note that in our scattering experiments all concentration series are obtained by repeatedly diluting a highly concentrated sample. We thus start at a high concentration where presumably particles of very high molar mass are present and reach, merely by dilution, the regime in which DNA solutions behave in the usual thermodynamic fashion. This demonstrates that the large particles must be formed by the DNA itself. The fact that above the critical concentrations the final values of $K c / R_{0}$ are about the same for all salt concentrations, suggests that the particles of high molar mass seem to be weakly perturbed by electrostatic interactions.

At $1 \mathrm{M} \mathrm{NaCl}$, measurements were duplicated with freshly isolated DNA: the anomalous scattering disappears at exactly the same concentration as before, and the complete curve is repeatable. This suggests that the particles of high molar mass are apparently stable at high DNA concentrations.

B. Structure Factor $\boldsymbol{S}(\boldsymbol{q})$. The structure factors $S(\boldsymbol{q})$ at 1 and $0.01 \mathrm{M} \mathrm{NaCl}$ are plotted in Figure $3 \mathrm{a}, \mathrm{b}$.

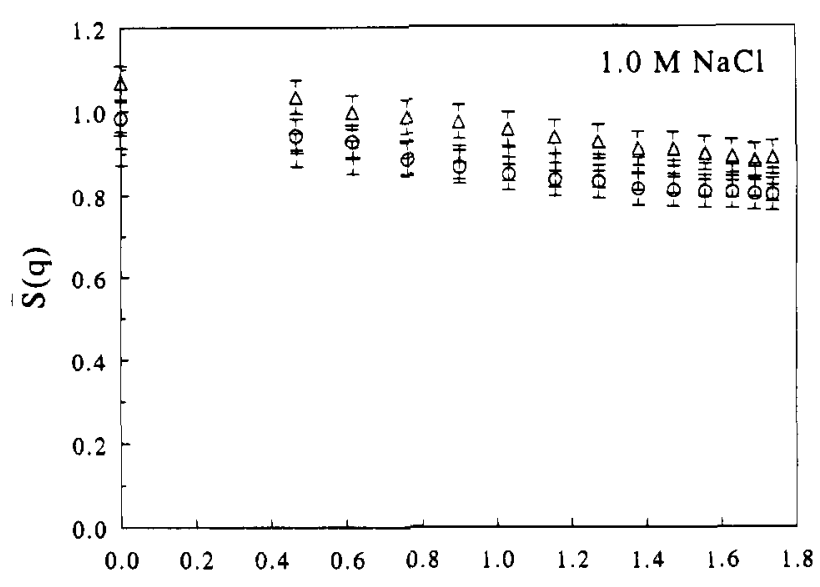

qL

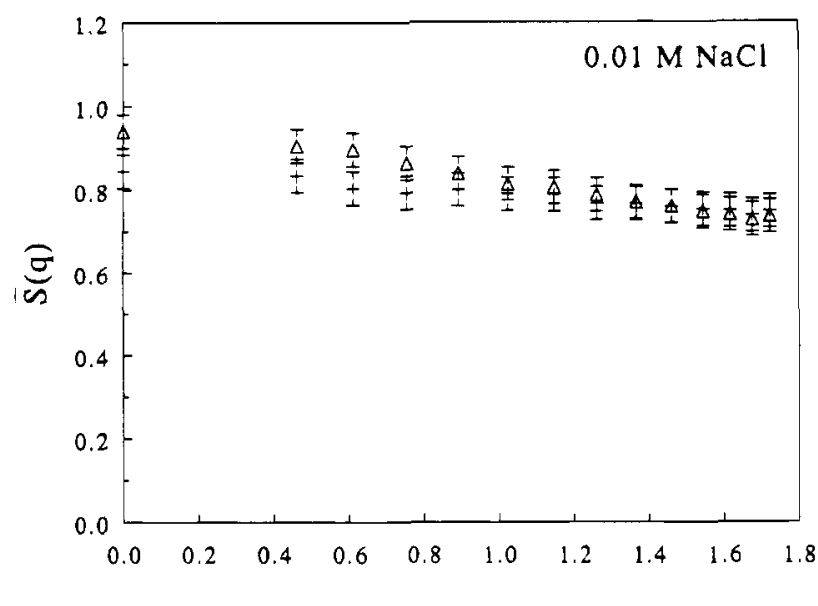

$\mathrm{qL}$

Figure 4. Structure factors at low DNA concentrations from Figure 3 are scaled on one single curve by taking into account the second and third virial coefficients. See text. (a, top) At $1 \mathrm{M}$ and (b, bottom) at $0.01 \mathrm{M} \mathrm{NaCl}$.

Although the experimental $q L$ range is rather small, we can deliberate on several features of the structure factor. Extrapolating the curves at lower concentrations to zero scattering angle, we find good agreement with the experiments performed with the KMX-6. At low DNA concentrations $S(\boldsymbol{q})$ decreases but flattens slightly with increasing DNA concentration. The structure factor at low ionic strength is lower than that at high ionic strength, because of interference of the scattered light caused by the stronger interactions in the former case. Here, we attempt to scale the structure factors at low DNA concentrations to one "master curve" in order to account for these interactions.

$$
\bar{S}(q) \equiv \frac{S(q)}{F(q)}\left(1+2 M A_{2} c F(q)+3 M A_{3} c^{2} F^{2}(q)\right)
$$

Equation 5 is semi-empirical and based on theoretical work $^{21-23}$ on slender charged rods in the second virial approximation. If we, however, perform the scaling up to the second virial coefficient, it is not very successful. The third virial term which is an educated guess, is included since its influence is substantial. ${ }^{36}$ The scaled data are plotted in Figure $4 a, b$. At $1 \mathrm{M} \mathrm{NaCl}$, we use the values of $A_{2}$ and $A_{3}$ from the second-order polynomial fits to the scattering data at zero scattering angle, summarized in Table 2. However, at $0.01 \mathrm{M}$ $\mathrm{NaCl}$, we decided to perform the scaling with an 

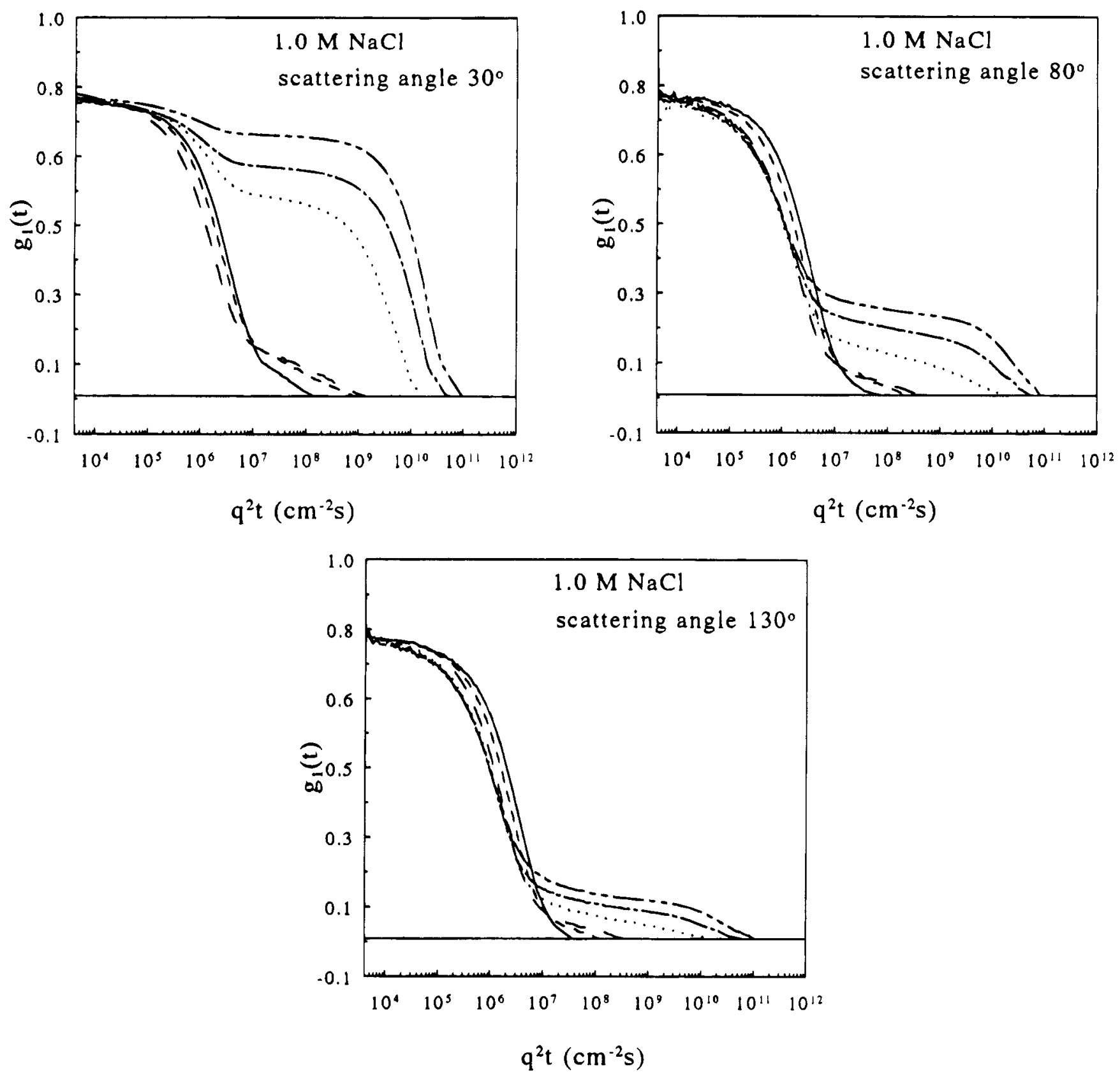

Figure 5. Reduced field-time correlation functions $g_{1}(t)$ for several DNA concentrations at $1 \mathrm{M} \mathrm{NaCl}$ : (-) $1.73 \mathrm{~g} / \mathrm{L}$, (- - -) 22.0 $\mathrm{g} / \mathrm{L},(---) 48.7 \mathrm{~g} / \mathrm{L},(\cdots) 71.5 \mathrm{~g} / \mathrm{L},\left(-\right.$ - $\left.^{-}\right) 90.4 \mathrm{~g} / \mathrm{L},(-\ldots-) 117 \mathrm{~g} / \mathrm{L}$

apparent negative "third virial coefficient" of $-3.0 \times$ $10^{-8} \mathrm{~L}^{2} \mathrm{~mol} \mathrm{~g} \mathrm{~g}^{-3}$, which describes the reverse curvature of the $K c / R_{0}$ curve caused by the increase of the total ionic strength with the DNA concentration. The data fall on one single curve for both ionic strengths within experimental error. Moreover, both curves are almost identical. Ideally, $\overline{\boldsymbol{S}}(\boldsymbol{q})$ should be identical to unity. However, the scaled curves display a residual $q$ dependence.

At low scattering angles the structure factor increases sharply beyond a concentration identical with the critical concentration in the experiments at zero scattering angle. This enhancement is greater with increasing DNA concentration, but it is almost independent of the ionic strength. At large scattering angles and at $1 \mathrm{M}$ $\mathrm{NaCl}$ the structure factor decreases slightly with the concentration, though not as fast as when the concentration is below critical, but remains more or less constant at $0.01 \mathrm{M} \mathrm{NaCl}$. In line with our assessment of the experiments at zero scattering angle, we interpret the considerable increase in forward scattering at high DNA concentrations as a substantial enhancement in the dimensions and molar mass of the scattering particles. The amplitude of the structure factor at high DNA concentrations exceeds unity, as the calculation of $S(\boldsymbol{q})$ is based on a constant molar mass equal to that of mononucleosomal DNA.

C. Dynamic Light Scattering. The correlation function $g_{1}(t)$ is plotted in Figures 5 and 6 versus logarithmic time in order to display the various relaxation regimes which are far apart. For clearness, the correlation functions are represented by way of so-called spline fits through the experimental points. All correlation functions decay to a zero baseline. Note that the amplitudes of the correlation functions depend on the DNA concentration, since the measurements were performed at different scattering volumes depending on the scattered intensity. In order to compare the relaxation modes, all amplitudes are scaled to one value at $q=0$. In Figure $5(1 \mathrm{M} \mathrm{NaCl})$ there are two distinct 

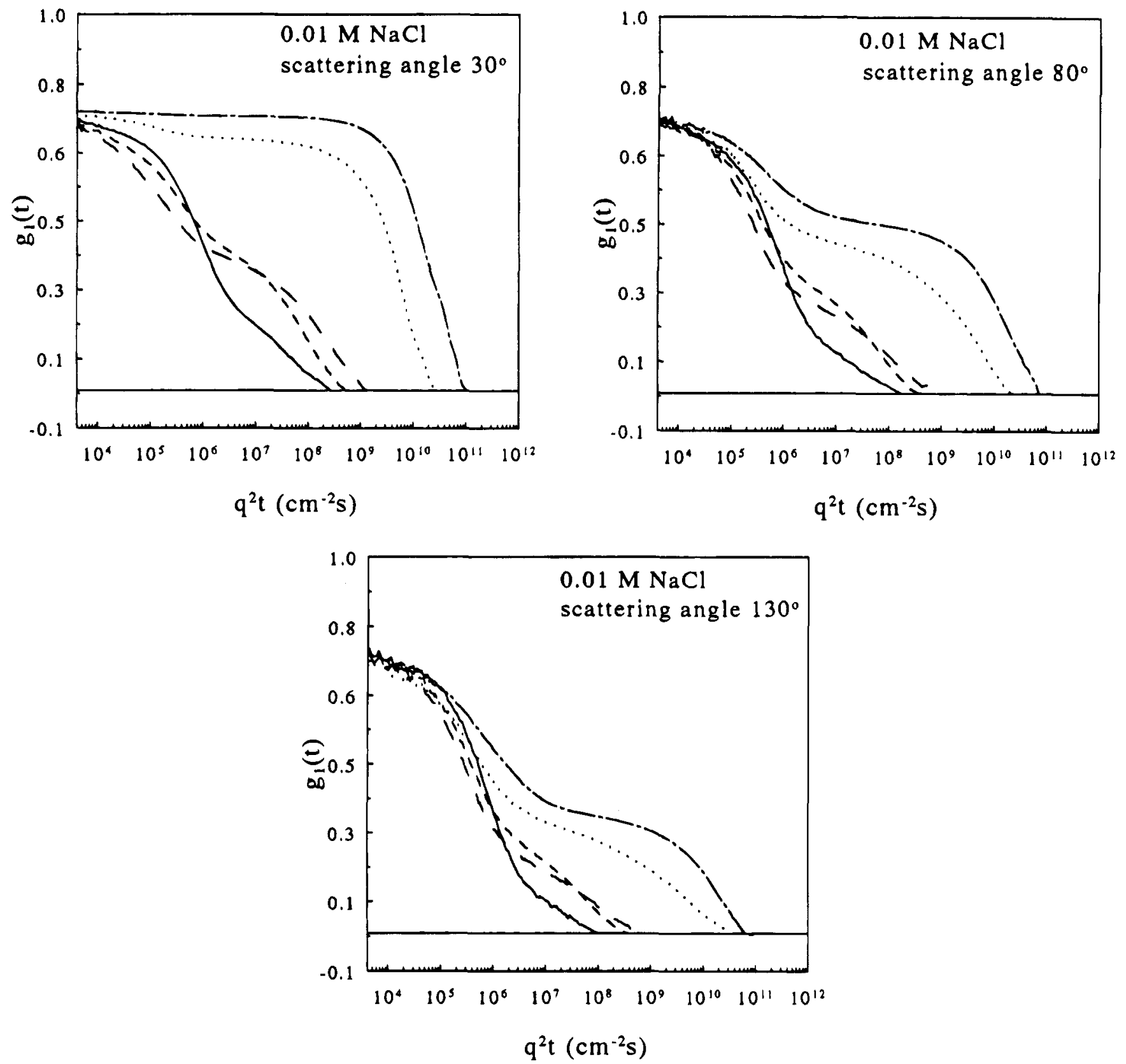

Figure 6. Reduced field-time correlation functions $g_{1}(t)$ for several DNA concentrations at $0.01 \mathrm{M} \mathrm{NaCl}:(-) 7.55 \mathrm{~g} / \mathrm{L},(--) 21.3$ $\mathrm{g} / \mathrm{L},(---) 42.8 \mathrm{~g} / \mathrm{L},(\cdots) 73.3 \mathrm{~g} / \mathrm{L},(---) 101 \mathrm{~g} / \mathrm{L}$.

DNA concentration regimes discernible. The three lowest concentrations show predominantly one relaxation mode at all scattering angles, which becomes faster with increasing DNA concentration. At the three highest DNA concentrations, which lie beyond the critical concentration determined by static light scattering, the correlation function displays an additional slow mode. The latter has a correlation time about 3 orders of magnitude greater than that of the "fast mode". Its contribution fo $g_{1}(t)$ is particularly large at low scattering angles. With increasing DNA concentration, the slow mode slows down even more and its contribution to $g_{1}(t)$ becomes larger. At $0.01 \mathrm{M} \mathrm{NaCl}$ (Figure 6), the trend is the same, although at the high end of the dilute regime there seems to be a "pretransitional regime", in which the additional slow mode is already present, but which is much faster and has a smaller contribution to $g_{1}(t)$ than in the concentrated regime beyond the critical concentration. In the latter the slow mode is slower and its contribution to $g_{1}(t)$ is larger than at $1 \mathrm{M} \mathrm{NaCl}$.

In order to gain qualitative insight into the slow mode, we plot the relative amplitude $A_{\text {slow }} /\left(A_{\text {fast }}+A_{\text {slow }}\right)$ determined by CONTIN (see below) as a function of the scattering angle and the DNA concentration in Figure $7 \mathrm{a}, \mathrm{b}$. We clearly see the jump in the relative amplitude at a concentration that corresponds to critical in the static case (at both ionic strengths). At $0.01 \mathrm{M} \mathrm{NaCl}$ we distinguish the intermediate regime, which is less clear or even absent in $1 \mathrm{M}$, and a more pronounced signature of the slow mode at large scattering angles.

In Figures 5 and 6, we see that, at low DNA concentrations, the fast mode becomes faster with increasing concentration, i.e. the apparent diffusion coefficient $\Gamma_{f}$ $q^{2}$ increases. At higher DNA concentrations the slow and fast modes overlap, which makes it difficult to assess the fast apparent diffusion coefficient. Therefore we apply CONTIN analyses to the $g_{1}(t)$ data as shown in Figure 8 (supplementary material) at low as well as high DNA concentrations. The distribution of relax- 

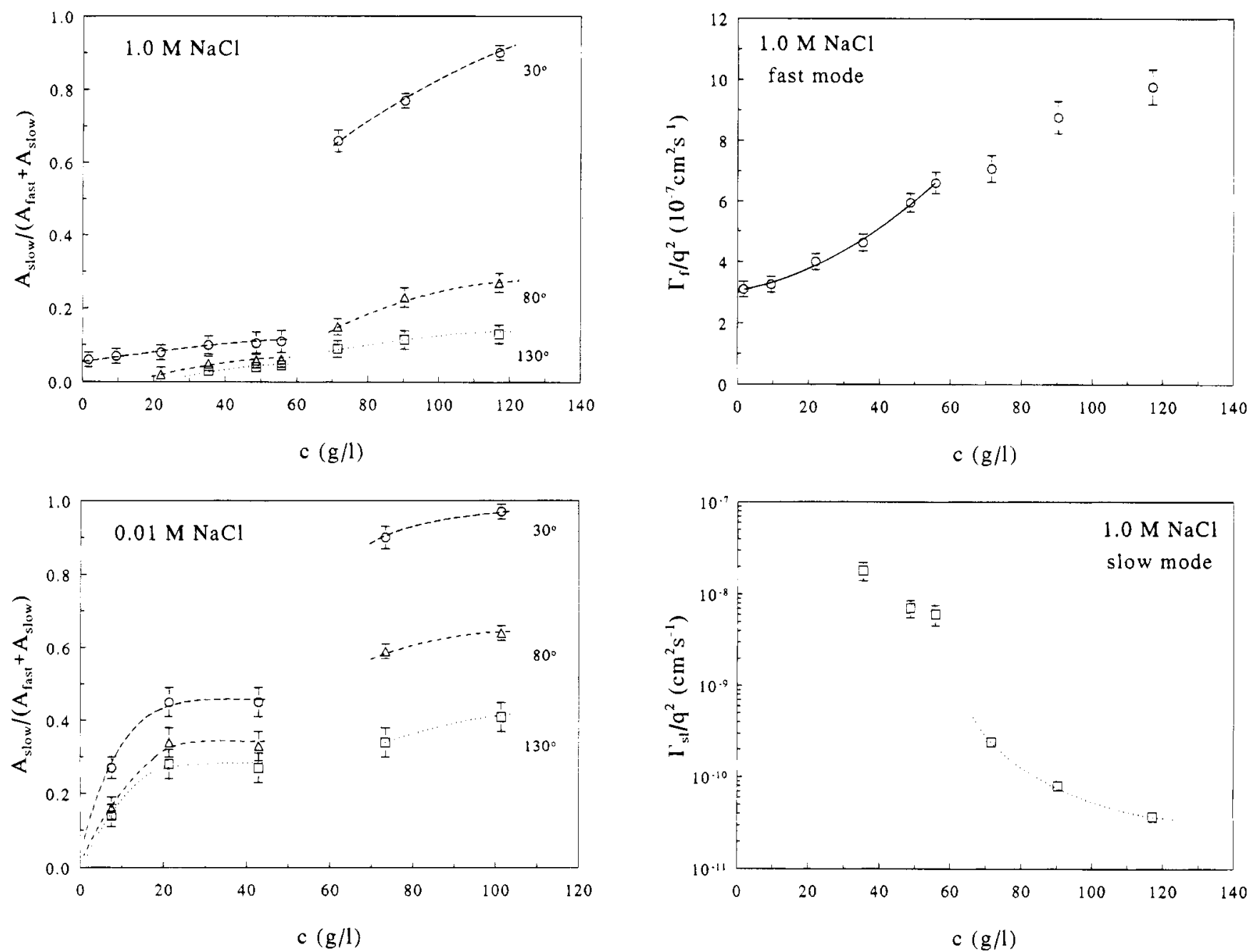

Figure 7. (a, top) Relative amplitude $A_{\text {slow }} /\left(A_{\text {fast }}+A_{\text {slow }}\right)$ of the slow mode within $g_{1}(t)$ as a function of DNA concentration at $1 \mathrm{M} \mathrm{NaCl}$. Scattering angles: $(O) 30^{\circ},(\triangle) 80^{\circ}$, and $(\square) 130^{\circ}$. The broken curves are guides to the eye. (b, bottom) Same as (a) but at $0.01 \mathrm{M} \mathrm{NaCl}$.

ation modes displays one or two well-separated modes for solutions of low DNA concentration. By contrast, in the concentrated solutions, particularly the highest at $0.01 \mathrm{M} \mathrm{NaCl}$, the distribution of the fast modes is broader. CONTIN displays the fast mode in the guise of several small peaks, which correspond to the broader peaks found in less concentrated solutions. The decay rates were determined from the peaks of the envelopes. The relative amplitudes of the fast and slow modes in the CONTIN analyses agree within the margin of error with the values estimated directly from the correlation functions $g_{1}(t)$ without any fitting procedure. In most cases a very fast decay is also detected, which is unlikely to be an artifact due to fast sampling times, for polystyrene in toluene does not display a similar fast decay under identical circumstances. The fast and slow apparent diffusion coefficients $\left(\Gamma_{\mathrm{f}} / q^{2}\right.$ and $\left.\Gamma_{\mathrm{s}} / q^{2}\right)$ extrapolated to zero scattering angle are plotted against the DNA concentration in Figures 9 and 10 and summarized in Table 3. In the low-concentration regime (up to 20 $\mathrm{g} / \mathrm{L}$ ) our curves are similar to those of previous studies. ${ }^{7,20}$ The coefficients extrapolated to zero DNA concentration are in agreement with those found by Nicolai and Mandel, ${ }^{7}$ although the extrapolation at $0.01 \mathrm{M} \mathrm{NaCl}$ is somewhat approximate because there are only few data. The diffusion expressed by $\Gamma_{f} / q^{2}$ is faster at low ionic strength. At moderate DNA concentrations the

Figure 9. Apparent diffusion coefficients $\Gamma / q^{2}$ at zero scattering angle as a function of DNA concentration at $1 \mathrm{M} \mathrm{NaCl}$ : (a, top) fast mode, (b, bottom) slow mode. Note that the slow mode is plotted logarithmically.

slopes at both ionic strengths are altered: the slope increases at $1 \mathrm{M}$ but decreases at $0.01 \mathrm{M} \mathrm{NaCl}$. In this regime the first signs of the slow mode are observed, again at both ionic strengths; the slow apparent diffusion coefficients are still rather fast and the amplitudes are low, especially at $1 \mathrm{M} \mathrm{NaCl}$. At the critical concentration the slow mode is retarded, as we saw in the qualitative analysis of the correlation functions, and the slow apparent diffusion coefficient decreases further with increasing DNA concentration. In the highly concentrated regime, the fast apparent diffusion coefficient keeps increasing although with a different slope. The fast and slow apparent diffusion coefficients deviate slightly but significantly from "purely diffusive" behavior; i.e. the plot of both $\Gamma_{f} / q^{2}$ and $\Gamma_{\mathrm{sl}} / q^{2}$ against $q^{2}$ is not a constant. In both salt solutions there is a positive slope associated with the slow mode although its magnitude is difficult to ascertain. The fast mode has a slope close to zero at low DNA concentrations and at $1 \mathrm{M} \mathrm{NaCl}$, but which becomes slightly positive at 0.01 $\mathrm{M} \mathrm{NaCl}$. Upon increasing the DNA concentration the slope turns negative at both ionic strengths.

The three scattering experiments are compatible with the assumption that slowly diffusing particles of high molar mass and large dimension are present in the solutions beyond a critical concentration. The latter increases with the salt concentration. The dynamic 

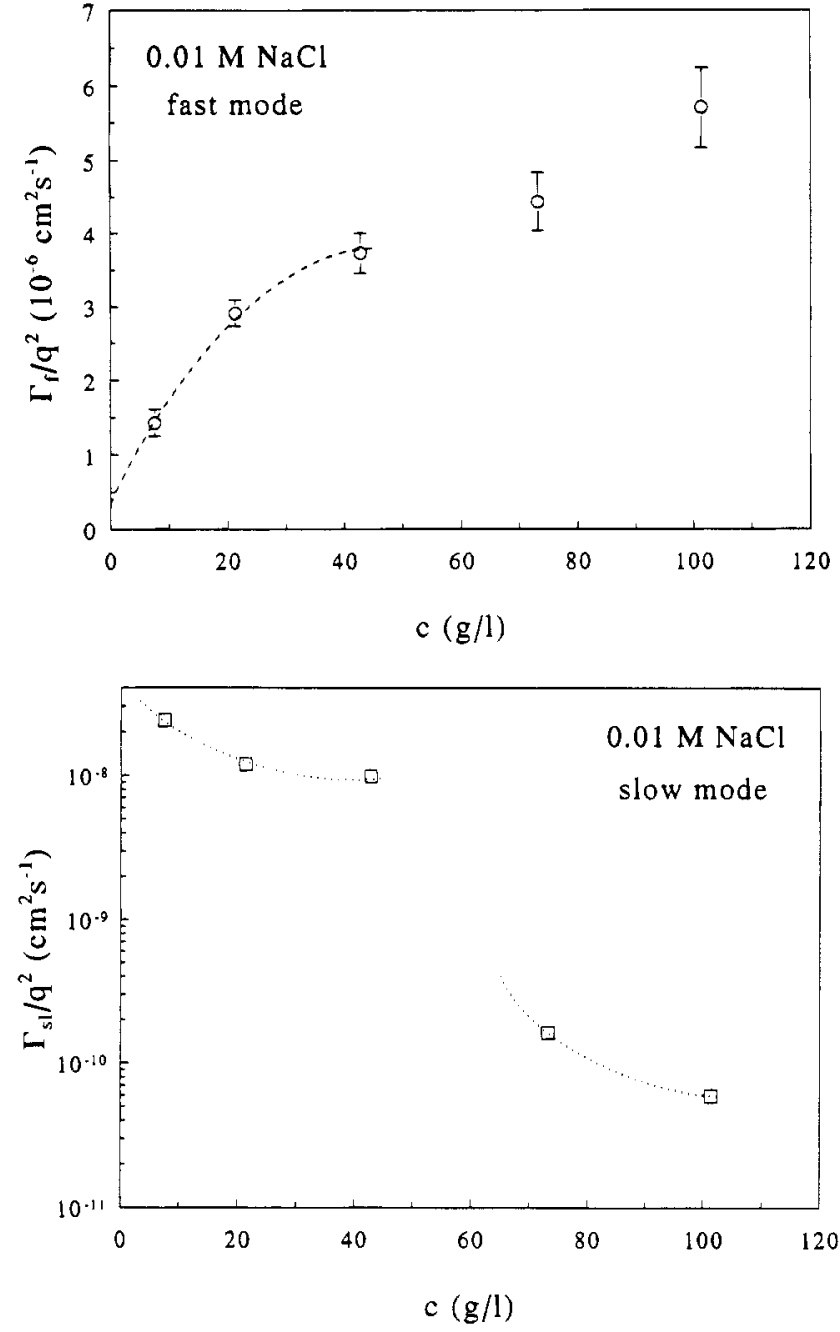

Figure 10. As in Figure 9, but at $0.01 \mathrm{M} \mathrm{NaCl}$.

Table 3. Apparent Diffusion Coefficients $\Gamma / q^{2}$ at Zero Scattering Angle as a Function of DNA Concentration at 1 and $0.01 \mathrm{M} \mathrm{NaCl}$ and at $25{ }^{\circ} \mathrm{C}$

\begin{tabular}{ccc}
\hline$c(\mathrm{~g} / \mathrm{L})$ & $\Gamma / q^{2}$, fast $\left(\mathrm{cm}^{2} / \mathrm{s}\right)$ & $\Gamma / q^{2}$, slow $\left(\mathrm{cm}^{2} / \mathrm{s}\right)$ \\
\hline & \multicolumn{1}{c}{$1 \mathrm{M} \mathrm{NaCl}$} \\
1.73 & $3.1 \times 10^{-7}$ & \\
9.50 & 3.3 & \\
22.0 & 4.0 & $1.8 \times 10^{-8}$ \\
35.3 & 4.6 & $7.0 \times 10^{-9}$ \\
48.7 & 6.0 & $6.0 \times 10^{-9}$ \\
55.8 & 6.6 & $2.4 \times 10^{-10}$ \\
71.5 & 7.1 & $8.0 \times 10^{-11}$ \\
90.4 & 8.8 & $3.7 \times 10^{-11}$ \\
117 & 9.8 & \\
& & \\
7.55 & $1.4 \times 10^{-6}$ & $2.4 \times 10^{-8}$ \\
21.3 & 2.9 & $1.2 \times 10^{-8}$ \\
42.8 & 3.7 & $9.9 \times 10^{-9}$ \\
73.3 & 4.4 & $1.6 \times 10^{-10}$ \\
101 & 5.7 & $6.0 \times 10^{-11}$
\end{tabular}

light scattering experiments suggest that an intermediate regime exists, particularly at low salt.

D. Viscosity. In Figure 11 we plot the relative viscosity increment $\eta_{\text {rel }}$

$$
\eta_{\mathrm{rel}}=\frac{\eta-\eta_{\mathrm{s}}}{\eta_{\mathrm{s}}}
$$

where $\eta$ is the viscosity of the DNA solution and $\eta_{\mathrm{s}}$ the viscosity of the solvent $(1 \mathrm{M} \mathrm{NaCl})$. In contrast with the light scattering experiments we do not see a transi-

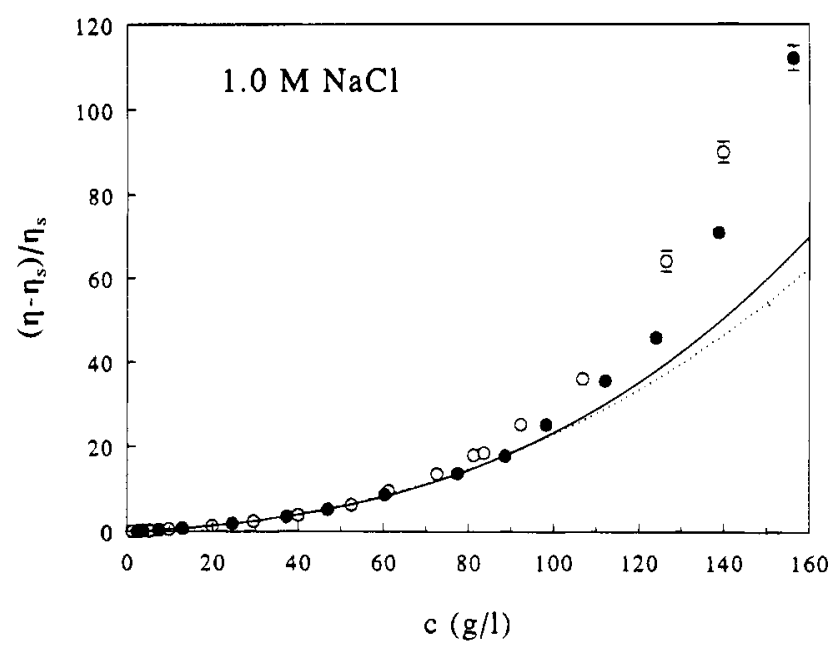

Figure 11. Relative viscosity increment as a function of DNA concentration at $1 \mathrm{M} \mathrm{NaCl}$. The curves display third-order polynomial fits: the full line fitted up to $47 \mathrm{~g} / \mathrm{L}$, the broken line up to $77 \mathrm{~g} / \mathrm{L} ;(\bigcirc)$ equilibrium, (৩) just after filtration.

tion in the viscosity. Nevertheless, the data at high DNA concentrations appear to deviate upward a bit from a naive extrapolation of $\eta_{\text {rel }}$ at lower concentrations to the concentrated regime. Moreover, the data beyond $80 \mathrm{~g} / \mathrm{L}$ do show distinct temporal effects: the viscosity measured initially (open symbols) is higher than the constant value reached after several days (closed symbols). Below the transition (at $75 \mathrm{~g} / \mathrm{L}$ ) found earlier, we fitted the data to a third-order polynomial, bearing in mind the predicted ${ }^{24}$ dependence of $\eta$ on $c^{3}$ for rods.

E. Electron Microscopy. The large particles inferred from the scattering experiments do in fact show up in the electron micrographs. In Figures 12 and 13 we show regions typical of those we find in carbon replicas of the surfaces of frozen samples. At $0.01 \mathrm{M}$ $\mathrm{NaCl}$, the micrographs of samples which were etched directly after freezing are similar to those of samples which were first broken and subsequently etched. At both ionic strengths, the samples abound with spherical globules whose surfaces have a flakelike texture. The distributions of the diameters of the globules are shown in Figure 14. Though we count fewer spheres at 0.01 $\mathrm{M} \mathrm{NaCl}$, the distributions are about the same at both ionic strengths if we take due care of statistical fluctuations. Note that our estimates of the sizes have to be taken with some reservation: the particles may have been situated deeper within the surface and larger than they seemed. At $1 \mathrm{M} \mathrm{NaCl}$ and at DNA concentrations below $75 \mathrm{~g} / \mathrm{L}$ only a small fraction-less than a few percent-of the carbon replicas shows similar particles though of a smaller size.

\section{Discussion}

Low-Concentration Regime: Rodlike Behavior. We have seen that the static light scattering data at zero scattering angle are described well by a virial expansion incorporating at least the second and third virial coefficients. Conversely, this expansion when extended to the scattering at nonzero angles is able to scale the experimental structure factors $S(q)$ to one master curve. The experimental values of the virial coefficients (Table 2) can be compared with the molecular virials $B_{\text {el }}$ and $C_{\text {el }}$, describing the electrostatic interactions between two and three polyions, respectively. In the derivation of the virial coefficients the 

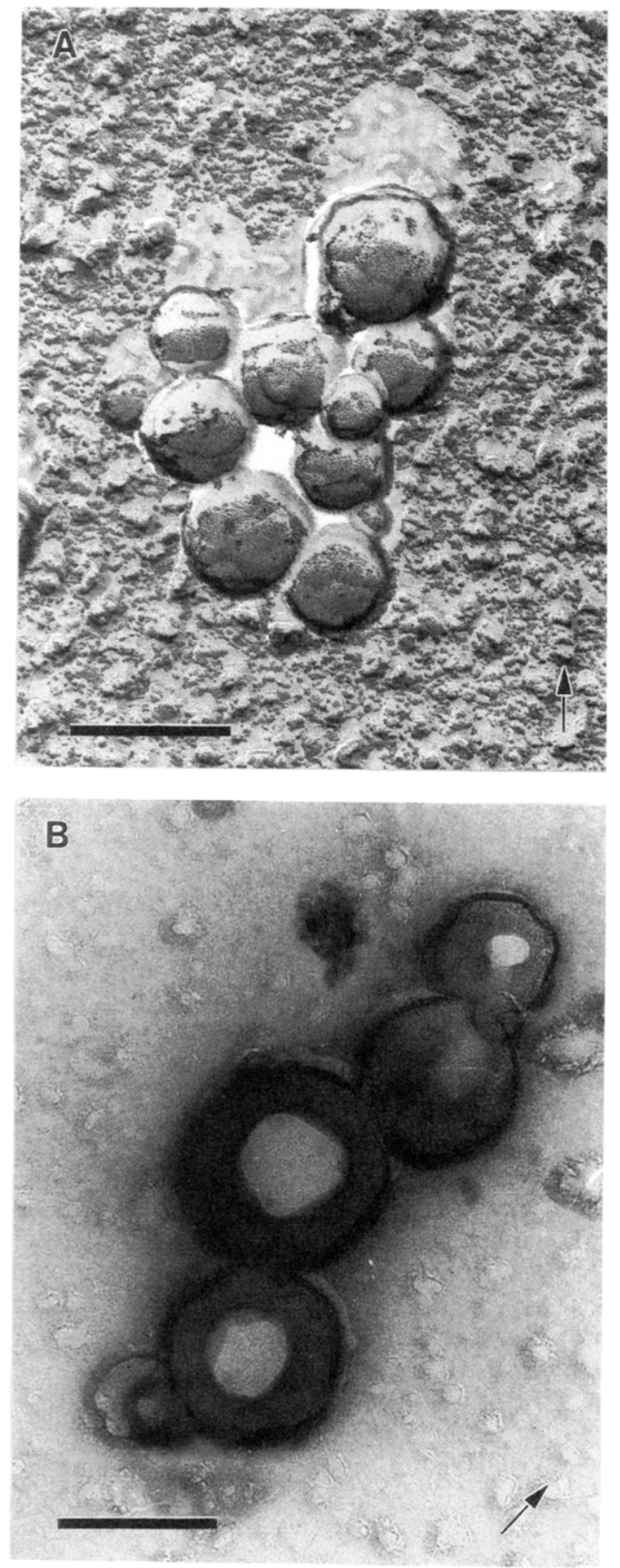

Figure 12. Electron cryographs for a $144 \mathrm{~g} / \mathrm{L}$ solution at $1 \mathrm{M}$ $\mathrm{NaCl}$. The bar corresponds to $300 \mathrm{~nm}$; the arrow represents the direction of $\mathrm{Pt}$ evaporation. In one micrograph (b) some globules appear to be toroids.

effective diameter, $d_{\text {eff, }}$ of stiff polyelectrolytes ${ }^{25-28}$ turns out to be a relevant length scale:

$$
d_{\text {eff }}=d+\kappa^{-1}\left(\ln A^{\prime}+\gamma+\ln 2-1 / 2\right)
$$

where $d$ is the bare diameter, $\gamma$ is Euler's constant, $\kappa^{-1}$ is the Debye length, and $A^{\prime}$ is a certain dimensionless parameter. ${ }^{28}$ How to compute this effective diameter is described in ref 28 . The molecular virial coefficients may be written as

$$
B_{\mathrm{el}, 0} \approx \frac{\pi}{4} L^{2} d_{\mathrm{eff}}
$$

or including end effects ${ }^{29}$
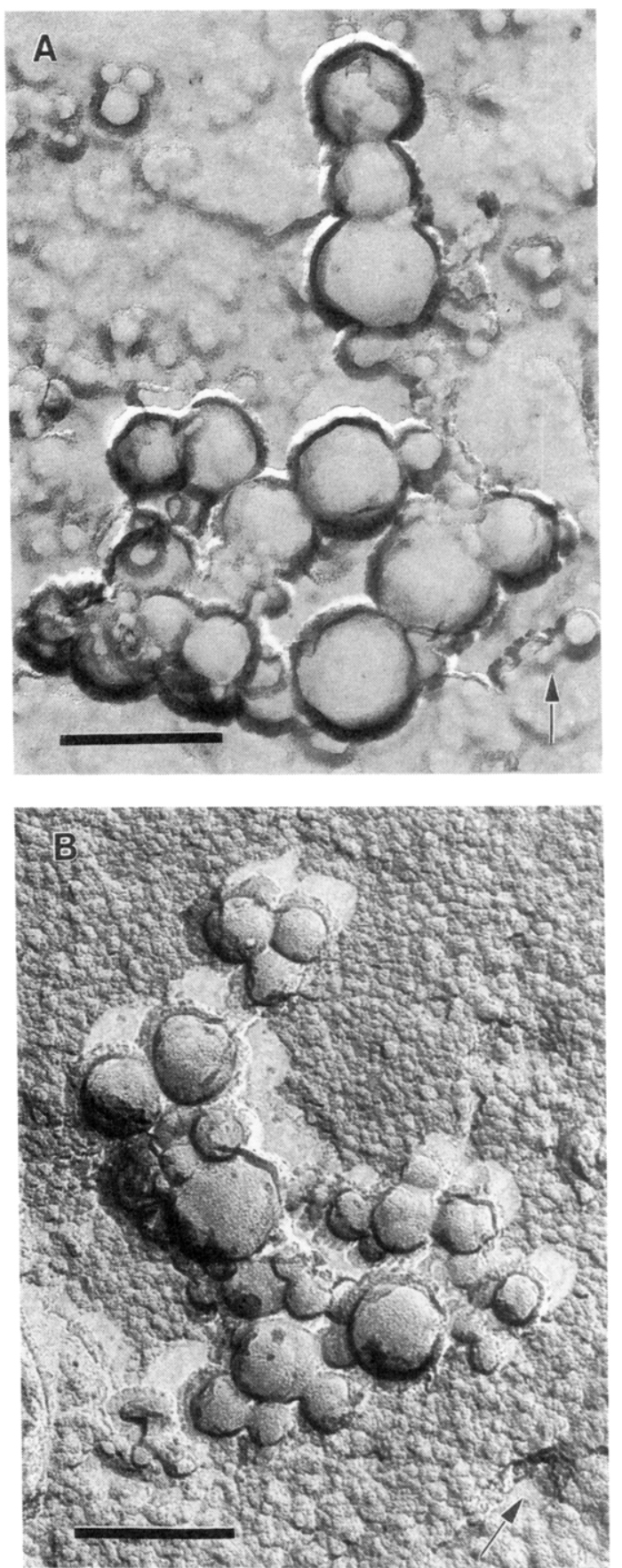

Figure 13. Electron cryographs for a $73 \mathrm{~g} / \mathrm{L}$ solution at 0.01 $\mathrm{M} \mathrm{NaCl}$. The bar corresponds to $300 \mathrm{~nm}$; the arrow represents the direction of Pt evaporation. The micrographs of samples which were etched directly after freezing (a) are similar to those of samples which were first broken and subsequently etched (b).

$$
B_{\mathrm{el}} \approx B_{\mathrm{el}, 0}\left(1+\frac{4 d_{\mathrm{eff}}}{L}\right)
$$

and $^{14}$

$$
C_{\mathrm{el}} \approx \frac{4 d_{\mathrm{eff}} B_{\mathrm{el}}^{2}}{L}
$$

Equation 10 is based on the asymptotic relation between $B_{\mathrm{el}, 0}$ and $C_{\mathrm{el}, 0}{ }^{30}$ which is valid for small $d_{\mathrm{eff}} / L$. Nevertheless, to account for end effects (though approximately) we use $B_{\text {el }}$ which does include end effects. Following ref 14 we evaluate the ratios of the experimental $A_{2}$ and $A_{3}$ to the respective molecular coefficients 

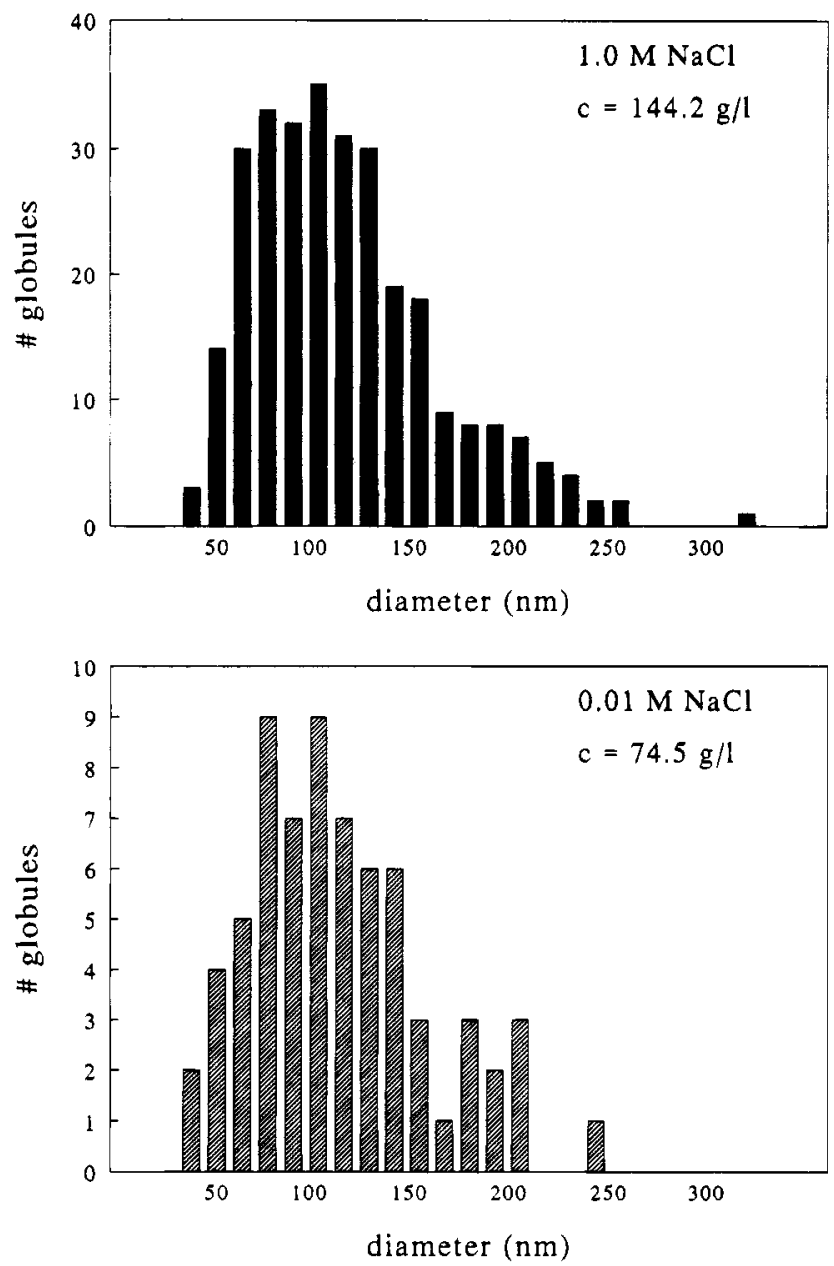

Figure 14. Distribution of diameters as observed in the electron cryographs: (a, top) at $1 \mathrm{M} \mathrm{NaCl}$ and (b, bottom) at $0.01 \mathrm{M} \mathrm{NaCl}$.

Table 4. Ratios $R_{2}$ and $R_{3}$ for Mononucleosomal DNA at $25^{\circ} \mathrm{C}$

\begin{tabular}{lcccccc}
\hline$n_{\mathrm{s}}(\mathrm{M})$ & $\kappa^{-1}(\mathrm{~nm})$ & $d_{\text {eff }}(\mathrm{nm})$ & $R_{2}$ & $R_{3}$ & $H$ & $h_{1}$ \\
\hline 1 & 0.30 & 2.73 & 0.76 & 0.68 & 0.49 & \\
0.1 & 0.96 & 5.49 & 0.74 & 0.30 & 0.90 & $\sim 30$ \\
0.01 & 3.04 & 13.7 & 0.85 & 0.13 & 2.57 &
\end{tabular}

$B_{\mathrm{el}}$ and $C_{\mathrm{el}}$ :

$$
\begin{gathered}
R_{2} \equiv \frac{M^{2} A_{2}}{N_{\mathrm{A}} B_{\mathrm{el}}} \\
R_{3} \equiv \frac{M^{3} A_{3}}{N_{\mathrm{A}}^{2} C_{\mathrm{el}}}
\end{gathered}
$$

where $N_{\mathrm{A}}$ is Avogadro's number (see Table 4). It must be pointed out that the values for $A_{3}$ at the two lower ionic strengths are upper bounds, since fits with more data at the higher concentrations would lead to lower values. The ratio $R_{2}$ is more or less the same for all ionic strengths, implying that the experimental second virial coefficient is consistent with electrostatic theories. ${ }^{25-29}$ However, the ratio $R_{3}$ decreases systematically with decreasing ionic strength: the experimental third virial coefficient is lower than predicted with the help of purely electrostatic interactions, the effect being more marked at low salt. One is inclined to attribute this third virial anomaly to attractive forces. Van der Schoot and Odijk ${ }^{31}$ showed that weak attractive forces may induce significant lowering of the third virial coefficient, while only slightly perturbing the second virial coefficient. Since attractive interactions sample in the main parallel configurations of test rods, higher body interactions are influenced to a greater extent. This is also reflected in the scattering by $1 \mathrm{M} \mathrm{NaCl}$ solutions where $K c / R_{0}$ in the intermediate regime, measured directly after filtration, is lower than when extrapolated beyond the dilute regime. Furthermore, a third-order polynomial fit to the former yields a fourth virial coefficient which is even negative.

In recent work, Odijk ${ }^{14}$ incorporated long-range attractive forces into polyelectrolyte theory. The amplitude $H$ of the attractive forces turns out to depend on the ionic strength. In ref 14 arguments for this dependence are advanced within two scenarios describing the interactions in different ways. The first is based on the "area of interaction", yielding an expression for $H_{1}$ :

$$
H_{1} \approx h_{1} \kappa^{-m}\left(a+\xi_{\mathrm{A}}\right) \xi_{\mathrm{A}}^{-m-1} \mathrm{e}^{2 \alpha / \xi_{\mathrm{A}}}
$$

Here $a=1 / 2 d$ is the radius of the polyion, $\xi_{\mathrm{A}}$ is a decay length of the attractive forces of about $14 \mathrm{~nm}$, which is unperturbed by the $1-1$ electrolyte, ${ }^{14} \kappa^{-1}$ is the Debye screening length $\left(\kappa^{2}=8 \pi Q n_{\mathrm{s}}\right.$ with $Q=0.714 \mathrm{~nm}$ the Bjerrum length in water at room temperature and $n_{\mathrm{s}}$ the concentration of the 1-1 electrolyte), and $h_{1}$ is a dimensionless coupling constant. In the second scenario the screening nature of the attractive interaction is viewed analogously to that of the electrostatic interaction. For $a \ll \xi_{\mathrm{A}}$ we have

$$
H_{2} \approx h_{2} \kappa^{-m} \frac{\pi a^{2}}{2 \xi_{\mathrm{A}}{ }^{m+2}}
$$

where $h_{2}$ is a coupling constant differing from $h_{1}$. The amplitude $H$ can be estimated experimentally by means of the ratio $R_{3}$ (for details see the original paper ${ }^{14}$ ). For hexagonal gels of tobacco mosaic virus it appears that $h \simeq h_{1} \simeq h_{2} \approx 10$. The second and third virial coefficients of rodlike xanthan ${ }^{15}$ were measured in detail in aqueous solution as a function of the ionic strength. As is the case for our mononucleosomal DNA, the ratio $R_{2}$ is constant more or less while $R_{3}$ decreases strongly with a lowering of the salt concentration. The values of $H$ evaluated from $R_{3}$ increase with decreasing ionic strength for both xanthan ${ }^{14}$ and DNA solutions (see Table 4). The data for xanthan can be fitted approximately to eq 13 with an exponent $m=1.5$ and coupling constnat $h_{1} \simeq 19$ if the first scenario were valid; in the case of the second scenario we obtain a value of about 103 for $h_{2} .{ }^{14}$ We have too few data on DNA to ascertain $m$. However, since DNA and xanthan are similar polyelectrolytes we conclude that $h_{1} \simeq 30$, judging from the respective $H$ values. The consistency of both values of $h_{1}$ for xanthan and DNA with the value of $h$ for the tobacco mosaic virus points to the consistency of scenario 1. For both DNA and xanthan the first scenario is in good agreement with certain macroscopic experiments on hydrophobic surfaces, where $h$ is about $20 .{ }^{14}$ Thus, in semidilute solutions of mononucleosomal DNA we tentatively discern signs of long-range attractive forces, which are stronger at low ionic strength.

In the semidilute regime the apparent diffusion coefficient at zero scattering angle $\Gamma_{\mathrm{f}} / q^{2}$ seems to display a concentration dependence similar to that of the inverse scattering intensity $K c / R_{0}$ (see Figures $9 \mathrm{a}$ and 10a). This is not unexpected since the apparent diffu- 


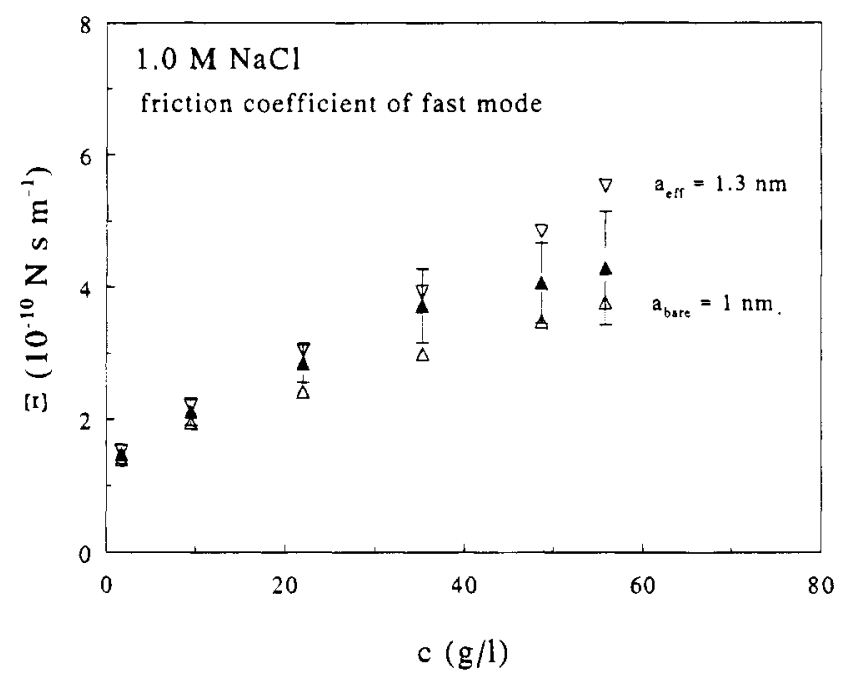

Figure 15. Friction coefficient $\Xi$ for mononucleosomal DNA at $1 \mathrm{M} \mathrm{NaCl}$ and $25^{\circ} \mathrm{C}$ : $(\Delta)$ experimentally determined $\Xi ;(\triangle)$ $\Xi$ calculated with a bare radius of $1 \mathrm{~nm} ;(\nabla) \Xi$ calculated with an effective radius of $1.3 \mathrm{~nm}$.

sion coefficient $\Gamma_{f} / q^{2}$, which may be assumed to be the cooperative diffusion coefficient $D_{\text {coop }}$, depends in part on the concentration via a virial expansion:

$$
\frac{\Gamma_{\mathrm{f}}}{q^{2}} \equiv D_{\text {coop }}=\frac{k_{\mathrm{B}} T}{\Xi}\left(1+2 M A_{2} c+3 M A_{3} c^{2}+\ldots\right)
$$

Here, $\Xi$ is the mutual friction coefficient of a DNA macromolecule. It is often thought ${ }^{7,9}$ that $\Xi$ is an analytic function of the concentration which may be written as a power series in $c$. However, the velocity field of a diffusing rod is of long range which leads to nonanalytic behavior of the friction. Odijk ${ }^{32}$ has given a simple Brinkman-type analysis of the theories of hydrodynamic screening by Freed and Edwards ${ }^{33}$ and Muthukumar and Edwards. ${ }^{34}$ The translational friction coefficient for a test rod moving in a semidilute solution of other rods is given by ${ }^{32}$

$$
\Xi=3 \pi \eta_{0} L K_{0}^{-1}\left(a / \xi_{\mathrm{H}}\right) \quad L \gg \xi_{\mathrm{H}}
$$

Here, $L$ is the length and $a$ the radius of the rod, $\eta_{0}$ is the solvent viscosity, $\xi_{\mathrm{H}}$ is the hydrodynamic screening length, and $K_{0}$ is the zero-order modified Bessel function of the second kind. The screening length at DNA concentration $c^{\prime}=\left(N_{\mathrm{A}} / M\right) c$, where $c^{\prime}$ is the number density, is evaluated with the help of the implicit relation $^{32,34}$

$$
\frac{K_{0}\left(a / \xi_{\mathrm{H}}\right)}{\xi_{\mathrm{H}}{ }^{2}}=3 \pi c^{\prime} L
$$

In Figure 15 we plot the experimentally determined friction coefficient from eq 15 at $1 \mathrm{M} \mathrm{NaCl}$ together with the theoretical coefficient from eq 16 calculated with a DNA radius of 1 or $1.3 \mathrm{~nm}$ : the precise hydrodynamic radius is not known a priori. At low DNA concentrations both curves virtually coincide irrespective of the choice for $a$. Note that it so happens that at very low concentrations the curves are nearly linear in $c$ for this particular polyelectrolyte. At moderate DNA concentrations the experimental curve is in between the two calculated plots, indicating that the hydrodynamic radius is of the order of $1 \mathrm{~nm}$, which seems reasonable. In view of this agreement between experiment and
Table 5. Results from the Aggregation Criterion for Mononucleosomal DNA at Several Ionic Strengths and at $25^{\circ} \mathrm{C}$

\begin{tabular}{lccccccc}
\hline$n_{\mathrm{s}}(\mathrm{M})$ & $I^{* a}(\mathrm{M})$ & $\kappa^{-1}(\mathrm{~nm})$ & $d_{\mathrm{eff}}(\mathrm{nm})$ & $c^{*}(\mathrm{~g} / \mathrm{L})$ & $\sigma_{3}$ & $H$ & $h_{1}$ \\
\hline 1 & 1.03 & 0.30 & 2.71 & 75 & 2.29 & 0.66 & \\
0.1 & 0.114 & 0.90 & 5.21 & 42 & 1.52 & 1.00 & $\sim 30$ \\
0.01 & 0.02 & 2.15 & 10.4 & 30 & 1.13 & 1.89 &
\end{tabular}

${ }^{a}$ Effective ionic strength $I^{*}$ at concentration $c^{*}: I^{*} \approx n_{\mathrm{s}}+$ $L /(2 M Q) \times c^{*}$.

theory, the influence of attractive interactions on the friction coefficient does not show up apparently. Again, this is what we expect at the pair level of interaction.

Intermediate-Concentration Regime: Transition Behavior. In Figure 2 we see that the critical concentration $c^{*}$ at which anomalies start to occur becomes lower as we decrease the ionic strength. This effect is counterintuitive since it would appear that at low ionic strength the effective diameter of the DNA rods is larger, making it more difficult to bring the charged particles close together. Nevertheless, in view of arguments put forward in the preceding section, long-range attraction may have a large impact on the structure of polyelectrolyte solutions. Since attractive interactions influence higher order virial coefficients more strongly than the second, the virial expansion may break down if the polyelectrolyte concentration exceeds a critical concentration. ${ }^{14,31}$ Thermodynamic instability (which may signal the onset of aggregation) is predicted by a provisional criterion: ${ }^{14}$

$$
1+2 B_{\mathrm{el}} c^{*} \approx-3 C\left(c^{*} *\right)^{2}
$$

in which $c^{*}=\left(N_{\mathrm{A}} / M\right) c^{*}$ is the critical number density and $C=M^{3} A_{3} / N_{\mathrm{A}}^{2}$ is the total molecular third virial coefficient consisting of a purely electrostatic contribution $C_{\mathrm{el}}$, a purely attractive contribution $C_{\mathrm{A}}$, and a cross term $C_{\mathrm{el}, \mathrm{A}}$ :

$$
C=C_{\mathrm{el}}+C_{\mathrm{el}, \mathrm{A}}+C_{\mathrm{A}}
$$

A relative contribution of the long-range attraction to $C$ can be described by ${ }^{14}$

$$
\sigma_{3} \equiv \frac{\left|C_{\mathrm{A}}+C_{\mathrm{el}, \mathrm{A}}\right|}{C_{\mathrm{el}}}
$$

Applying the criterion given by eq 18 to the transition observed in the scattering behavior of DNA yields $\sigma_{3}$ and consequently $H$, which are summarized in Table 5 (for details see ref 14). Again, there are too few data to determine $m$. A comparison with xanthan ${ }^{15}$ yields $h_{1}$ $\simeq 30$, which is more or less the same as the value found in the analysis of the ratio $R_{3}$ for mononucleosomal DNA in the previous section.

Concentrated Regime: Particles of High Molar Mass. A quantitative explanation of our measurements in this regime evidently must employ a complicated aggregational model involving DNA rods and DNA globules. In addition, the interactions appear to cancel at the onset of aggregation so that some sort of critical slowing down may be involved in the slow diffusive mode. We do not enter into these delicate theoretical problems here but instead give a qualitative picture which appears to be reasonably consistent with most of our data.

(a) Let us assume the aggregates in the concentrated regime are in the main typically a loose bunch of DNA globules each of diameter $D=O(100 \mathrm{~nm})$ in equilibrium 
with a suspension of nonaggregating DNA rods. We suppose the fraction of DNA rods enclosed within the aggregates is $f=O(0.1)$ and the size $\Delta$ of an aggregate is about $500 \mathrm{~nm}$ (i.e. $\Delta \gg L$, the length of a DNA rod).

(b) Although we believe the DNA rods within the globules are held together by long-range attractive forces (the usual dispersion forces are simply too weak), the globules themselves may well stick to each other within a secondary minimum arising from the balance of double layer repulsion and van der Waals attraction. The electrostatic repulsion would have to be analyzed carefully, but we do know that the secondary minimum is situated at several times the Debye length away from the surface of a globule. The van der Waals attraction between two globules is roughly given by a Hamaker expression:

$$
U_{\mathrm{W}} \simeq-\frac{g W D}{24 b}
$$

where $W$ is the Hamaker constant $\left(=O\left(k_{\mathrm{B}} T\right)\right.$ for DNA), $g$ is the volume fraction of DNA within a globule $(g=$ $O(0.1)$ ), and $b$ is the separation between the globular surfaces. With $D=O(100 \mathrm{~nm})$ and $b=O(1 \mathrm{~nm})$ we have $U_{\mathrm{W}}=-O\left(k_{\mathrm{B}} T\right)$.

(c) The electrostatic self-volume $\left(\equiv^{1 / 4} \pi L d_{\mathrm{eff}^{2}}\right)$ of a DNA rod at $1 \mathrm{M} \mathrm{NaCl}$ is about $300 \mathrm{~nm}^{3}$; so a globule of 100 $\mathrm{nm}$ diameter consists of about $10^{2} \mathrm{DNA}$ rods since the rods are not likely to be close-packed $(g=O(0.1))$. An aggregate thus contains about $10^{3}$ rods (there are about 10 globules within one aggregate; see Figures 12 and $13)$. Hence, the reciprocal intensity $K c / R_{0}$ should be of order $f^{-1} \times 10^{-3} \times 10^{-5} \simeq 10^{-7} \mathrm{~mol} / \mathrm{g}$, in agreement with Table 1.

(d) The interference factor pertaining to a single aggregate is some unknown complicated function $\phi(q \Delta, q D)$ with $\phi \rightarrow 1$ as $q \rightarrow 0$ and $\phi \ll 1$ for $q \Delta \gg 1$. Accordingly, for $q L>1$ the interference within an aggregate is destructive enough for the scattering by it to become negligible. In Figure $3 a$ and $b$ the scattering curves indeed converge toward the curves one expects for concentrated suspensions of unaggregated DNA rods (noting that $f \simeq 0.1$ ).

(e) For similar reasons we see low amplitudes of the slow decay in the correlation function $g_{1}(t)$ at a scattering angle of $130^{\circ}(q L=1.5 ; q \Delta \gg 1$; see Figures 5 and 6). By contrast, at $30^{\circ}$ (i.e. $q L=0.46$ or $q \Delta \simeq 2$ ) it is not unreasonable to see large contributions from the slow mode. We have also plotted the scattering vector dependence of the relative intensity of the slow mode in Figure 16.

(f) Even if only about $10 \%$ of the rods aggregate, the viscosity of the entangled suspension of remaining DNA rods decreases by a substantial amount (down the curve represented by the white circles in Figure 11). The much more compact aggregates of size $\Delta$ which diffuse through the surrounding suspension of entangled unaggregated rods, enhance the viscosity by only a very small amount approximately proportional to the aggregate volume fraction. On the whole, the viscosity should decrease upon aggregation, and this is what is seen in Figure 11.

(g) In Table 3 , the ratio $\left(\Gamma_{\mathrm{s} l} / q^{2}\right) /\left(\Gamma_{f} / q^{2}\right)$ is very low, $10^{-3}-10^{-4}$. However, this is misleading: we should actually regard the diffusion of the aggregates in the effective medium of nonaggregating DNA rods. Hence, we also plot $\eta \Gamma_{\mathrm{sl}} / q^{2}$ in Figure 17 which is a much more slowly varying function than $\Gamma_{\mathrm{s}} / q^{2}$ itself. The ratio $\left(\eta \Gamma_{\mathrm{s}} /\right.$ $\left.q^{2}\right) /\left(\eta_{\mathrm{s}} \Gamma_{\mathrm{f}} / q^{2}\right)=10^{-2}$, which is comprehensible to some

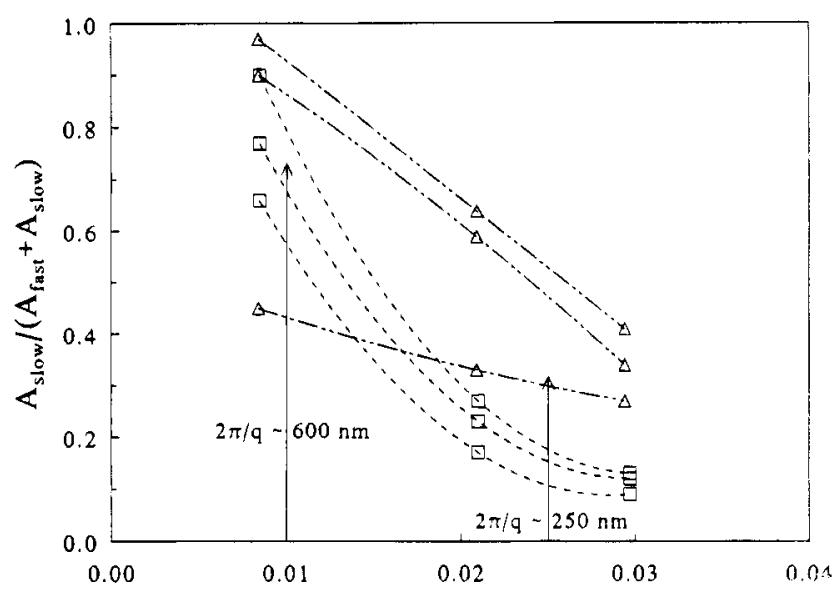

$\mathrm{q}\left(\mathrm{nm}^{-1}\right)$

Figure 16. Relative contribution of the slow mode plotted against the scattering vector $q$ : $(\square) 1 \mathrm{M}$ and $(\triangle) 0.01 \mathrm{M} \mathrm{NaCl}$. The larger the relative contribution, the higher the DNA concentration.

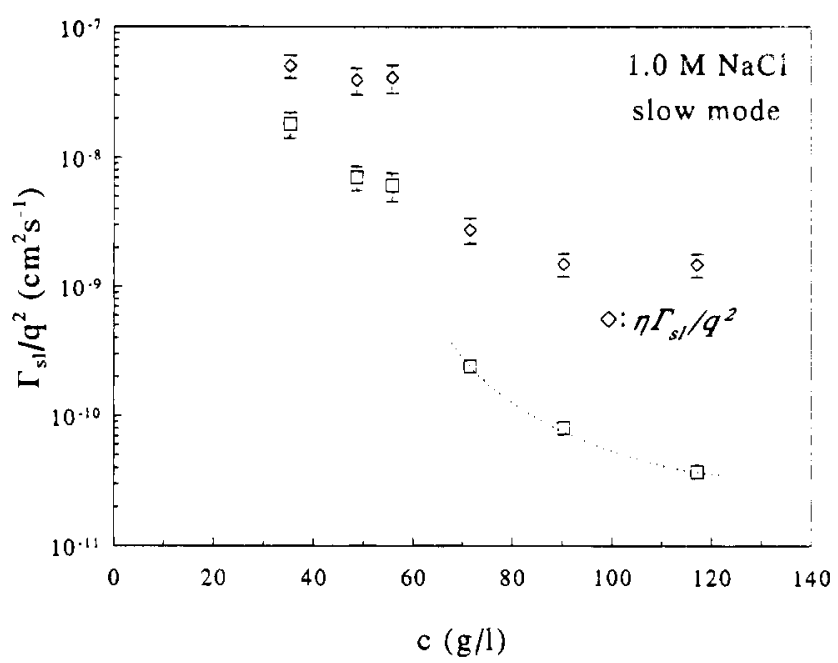

Figure 17. Apparent slow diffusion coefficient at $1 \mathrm{M}$, together with the coefficient multiplied by the viscosity at the relevant DNA concentration.

extent in terms of the increase in the effective Stokes radius from $L$ to $\Delta$ and the effect of thermodynamic slowing down.

(h) One piece of evidence appears to disagree with our qualitative picture. Because $\Delta$ is given by the balance of eq 21 and the electrostatic repulsion between two globules, $\Delta$ ought to be sensitive to the ionic strength. However, the slow mode does not appear to depend on the salt concentration (Figure 18).

\section{Concluding Remarks}

Although we have made obvious precautions to eliminate heavy metallic ions, it is conceivable that very minute (undetectable?) quantities of contaminants might be causing the DNA to aggregate. If that were the case. it is very difficult to understand the remarkable salt dependence of the onset of aggregation as monitored by static light scattering. We have shown that the aggregation does seem to fit within the theoretical framework of long-range attraction hypothesized in ref 14 . In particular, the coupling constant $h_{1}$ for DNA is in reasonable agreement with those for xanthan and tobacco mosaic virus. ${ }^{14}$ Clearly, more experiments related to these issues are warranted. 


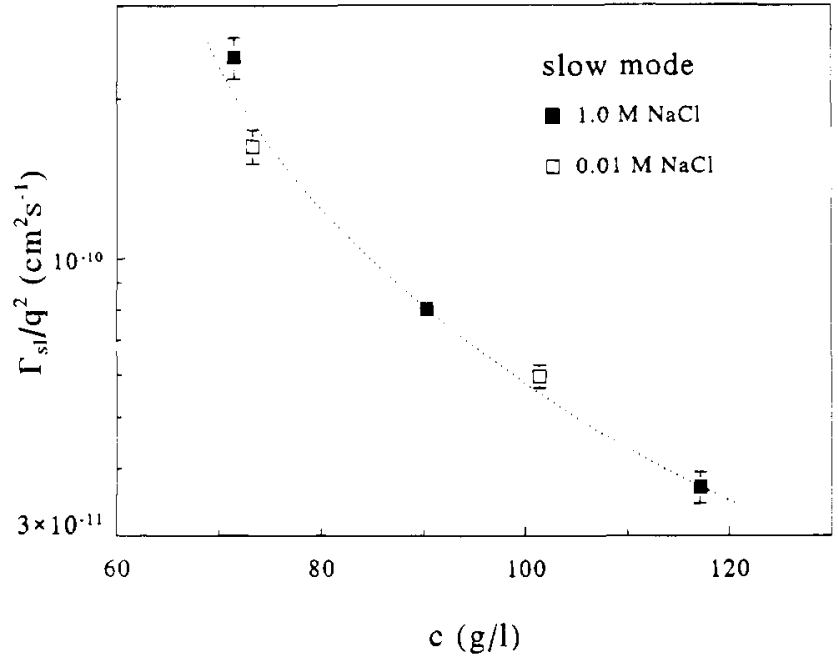

Figure 18. Apparent slow diffusion coefficients at $1 \mathrm{M}$ and $0.01 \mathrm{M} \mathrm{NaCl}$ forming one single curve.

Note Added in Proof: In eq 5 the term proportional to $A_{3}$ is only a qualitative estimate. A detailed computation ${ }^{36}$ shows that the interference factor is not $F^{2}(q)$ but rather more like $F(q)$. If we had taken this into account, the scaling in Figure 4 would have been altered only slightly since $q L<2$.

J. van Dijk (Gorlaeus Laboratories, Leiden) has characterized approximately the distributions of the molar mass for various DNA samples prepared according to the procedure of ref 17 by GPC methods outlined previously. ${ }^{38}$ The sample used in measurements presented here is slightly more polydisperse than what one would expect from the data given by Wang et al. ${ }^{17} \mathrm{~A}$ second sample turns out to be more polydisperse with a substantially larger number of smaller fragments. However, we find that Figure 2a is repeatable within the margin of error. The degree of polydispersity of other samples prepared at the Gorlaeus Laboratories varies (see for instance ref 39). This conforms with the observation of Sikorav et al., 37 who found that DNA prepared by the method of Strzelecka and Rill ${ }^{40}$ may also be fairly polydisperse.

Acknowledgment. We thank Wim Jesse for performing a substantial part of the DNA isolation procedure and Fer Spies and Joost van't Noordende of the Electron Microscopy Department, Faculty of Medical Science, Leiden University, for performing the electron microscopy experiments. Unilever Research Laboratorium Vlaardingen is gratefully acknowledged for putting measuring time on their refractometer at our disposal; Nico Hoekstra is acknowledged for assistance. We thank Ies Heertje of the Electron Microscopy Department, Unilever Research Laboratorium Vlaardingen, for useful comments on the electron micrographs. T.O. thanks J. R. C. van der Maarel, J. van Dijk, J. L. Sikorav, and F. Livolant for discussions.

Supplementary Material Available: Figure 8 showing CONTIN plots at scattering angles of 30,80 , and $130^{\circ}$, for two solutions, one of low and one of high DNA concentration, at both 1 and $0.01 \mathrm{M} \mathrm{NaCl}$ (2 pages). Ordering information is given on any current masthead page.

\section{References and Notes}

(1) Mandelkern, M.; Dattagupta, N.; Crothers, D. M. Proc. Natl. Acad. Sci. USA 1981, 78, 4294 .

(2) Fulmer, A. W.; Benbasat, J. A.; Bloomfield, V. A. Biopolymers $1981,20,1147$.

(3) Fried, M. G.; Bloomfield, V. A. Biopolymers 1984, 23, 2141.

(4) Bloomfield, V. A. In Reversible Polymeric Gels and Related Systems; Russo, P. S., Ed.; American Chemical Society: Washington, DC, 1987; pp 199-210.

(5) Härd, T; Kearns, D. R. Biopolymers 1986, 25, 438.

(6) Nicolai, T.; Mandel, M. Macromolecules 1989, 22, 438.

(7) Nicolai, T.; Mandel, M. Macromolecules 1989, 22, 2348

(8) Wang, L.; Garner, M. M.; Yu, H. Macromolecules 1991, 24, 2368 .

(9) Goinga, H. T.; Pecora, R. Macromolecules 1991, 24, 6128.

(10) Strzelecka, T. E.; Davidson, M. W.; Rill, R. L. Nature 1988, $331,457$.

(11) Strzelecka, T. E.; Rill, R. L. J. Phys. Chem. 1992, 96, 7796.

(12) Trohalaki, S.; Brian, A. A.; Frisch, H. L.; Lerman, L. S. Biophys. J. 1984, 45, 777.

(13) Wissenburg, P.; Odijk, T.; Cirkel, P.; Mandel, M. Macromolecules 1994, 27, 306 .

(14) Odijk, T. Macromolecules 1994, 27,4998. There is a mistake in the section "Application to the Hexagonal Phase of TMV". For tobacco mosaic virus, we should have $H=h \hat{\lambda} a \xi_{\mathrm{A}}{ }^{-2} \exp (2 \alpha /$ $\xi_{\mathrm{A}}$ ) so $h \approx 10$ (instead of 40 ).

(15) Kawakami, K.; Norisuye, T. Macromolecules 1991, $24,4898$.

(16) Millman, B. M.; Irving, T. C.; Nickel, B. G.; Loosley-Millman, M. E. Biophys. J. 1984, 45, 551 .

(17) Wang, L.; Ferrari, M.; Bloomfield, V. A. Biotechniques 1990 , $9,24$.

(18) Einaga, Y.; Abe, F.; Yamakawa, H. J. Phys. Chem. 1992, 96, 3948.

(19) Provencher, S. W. Comput. Phys. 1982, 27, 213 and 229

(20) Ferrari, M. E.; Bloomfield, V. A. Macromolecules 1992, 25, 5266.

(21) Van der Schoot, P.; Odijk, T. Macromolecules 1990, 23, 4181.

(22) Maeda, T. Macromolecules 1991, 24, 2740.

(23) Odijk, T. In Laser Light Scattering in Biochemistry; Sattelle, D.; Harding, S., Bloomfield, V. A., Eds.; Royal Society of Chemistry: London, 1992; Chapter 12.

(24) Doi, M.; Edwards, S. F. The Theory of Polymer Dynamics; Oxford University Press: Oxford, U.K., 1986

(25) Onsager, L. Ann. N.Y. Acad. Sci. 1949, 51, 627.

(26) Stigter, D. Biopolymers 1977, 16, 1435.

(27) Fixman, M.; Skolnick, J. Macromolecules 1978, 11, 863.

(28) Stroobants, A.; Lekkerkerker, H. N. W.; Odijk, T. Macromolecules 1986, 19, 2232.

(29) Odijk, T. J. Chem. Phys. 1990, 93, 5172.

(30) Odijk, T. Macromolecules 1986, 19, 2313

(31) Van der Schoot, P.; Odijk, T. J. Chem. Phys. 1992, 97, 515.

(32) Odijk, T. Macromolecules 1986, 19, 2073.

(33) Freed, K. F.; Edwards, S. F. J. Chem. Phys. 1974, 61, 3626.

(34) Muthukumar, M.; Edwards, S. F. Macromolecules 1983, 16 , 1475.

(35) This value agrees with that found by Strzelecka and Rill (Strzelecka, T.E.; Rill, R. L. Macromolecules 1991, 24, 5124). Hence, there is a "normal" isotropic-to-cholesteric transition despite the aggregation phenomenon.

(36) For a quantitative theory up to and including the third virial term, see: Odijk, T. In Light Scattering, Principles and Development; Brown, W., Ed.; Oxford University Press, in press.

(37) Sikorav, J. L.; Pelta, J.; Livolant, F. Biophys. J., in press.

(38) Nicolai, T.; van Dijk, L.; van Dijk, J. A. P. P.; Smit, J. A. M. J. Chromatogr. 1987, 389, 286.

(39) Groot, L. C. A.; Kuil, M. E.; Leyte, J. C.; van der Maarel, J. R. C.; Heenan, R. K.; King, S. M.; Jannink, G. Liq. Cryst. 1994, 17, 263.

(40) Strzelecka, T. E.; Rill, R. L. J. Am. Chem. Soc. 1987, 109, 4513.

MA945017E 